University of Wollongong

Research Online

Australian Institute for Innovative Materials -

Papers

Australian Institute for Innovative Materials

$1-1-2018$

Graphene-Tailored Thermodynamics and Kinetics to Fabricate Metal Borohydride Nanoparticles with High Purity and Enhanced Reversibility

Hongyu Zhang

Fudan University

Guanglin Xia

University of Wollongong,gx168@uowmail.edu.au

Jian Zhang

Changsha University of Science And Technology

Dalin Sun

Fudan University, Shanghai Innovation Institute for Materials

Zaiping Guo

University of Wollongong, zguo@uow.edu.au

See next page for additional authors

Follow this and additional works at: https://ro.uow.edu.au/aiimpapers

Part of the Engineering Commons, and the Physical Sciences and Mathematics Commons

Research Online is the open access institutional repository for the University of Wollongong. For further information contact the UOW Library: research-pubs@uow.edu.au 


\title{
Graphene-Tailored Thermodynamics and Kinetics to Fabricate Metal Borohydride Nanoparticles with High Purity and Enhanced Reversibility
}

\author{
Abstract \\ Due to their ultrahigh theoretical capacity, metal borohydrides are considered to be one of the most \\ promising candidate hydrogen storage materials. Their application still suffers, however, from high \\ operating temperature, sluggish kinetics, and poor reversibility. Designing nanostructures is an effective \\ way of addressing these issues, but seeking suitable approaches remains a big challenge. Here, a space- \\ confined solid-gas reaction to synthesize $\mathrm{Mg}(\mathrm{BH} 4) 2$ nanoparticles supported on grapheme is reported, \\ which serves as the structural support for the dispersed $\mathrm{Mg}(\mathrm{BH} 4) 2$ nanoparticles. More notably, density \\ functional theory calculations reveal that graphene could weaken both the $\mathrm{Mg} \curvearrowright \mathrm{H}$ bonds of $\mathrm{MgH} 2$ and \\ $\mathrm{B} \gg \mathrm{B}$ bonds of $\mathrm{B} 2 \mathrm{H} 6$, which could thermodynamically and kinetically facilitate the chemical \\ transformation to synthesize $\mathrm{Mg}(\mathrm{BH} 4) 2$ with high purity. Because of the synergistic effects of both the \\ significant reduction in particle size and the catalytic effect of graphene, an onset dehydrogenation \\ temperature of $\approx 154^{\circ} \mathrm{C}$ is observed for $\mathrm{Mg}(\mathrm{BH} 4) 2$ nanoparticles, and a complete dehydrogenation \\ could be achieved at a temperature as low as $225^{\circ} \mathrm{C}$, with the formation of $\mathrm{MgB} 2$ as the by-product. This \\ work provides a new perspective to tailoring the thermodynamics and kinetics of chemical reactions \\ toward the favorable synthesis of functional inorganic materials.

\section{Disciplines} \\ Engineering | Physical Sciences and Mathematics

\section{Publication Details} \\ Zhang, H., Xia, G., Zhang, J., Sun, D., Guo, Z. \& Yu, X. (2018). Graphene-Tailored Thermodynamics and \\ Kinetics to Fabricate Metal Borohydride Nanoparticles with High Purity and Enhanced Reversibility. \\ Advanced Energy Materials, 8 (13), 1702975-1-1702975-9.
}

\section{Authors}

Hongyu Zhang, Guanglin Xia, Jian Zhang, Dalin Sun, Zaiping Guo, and Xuebin Yu 


\section{WILEY-VCH}

DOI: 10.1002/ ((please add manuscript number))

Article type: Full Paper

\section{Graphene-Tailored Thermodynamics and Kinetics to Fabricate Metal Borohydride Nanoparticles with High Purity and Enhanced Reversibility}

Hongyu Zhang, Guanglin Xia, * Jian Zhang, Dalin Sun, Zaiping Guo, Xuebin Yu*

H. Y. Zhang, Prof. D. L. Sun, Prof. X. B. Yu

Department of Materials Science, Fudan University, Shanghai 200433, China

E-mail: yuxuebin@fudan.edu.cn

Dr. G. L. Xia, Prof. Z. P. Guo

Institute for Superconducting and Electronic Materials, University of Wollongong, North

Wollongong, NSW 2522, Australia

E-mail: guanglin@uow.edu.au

Dr. J. Zhang

College of Automotive and Mechanical Engineering, Changsha University of Science and

Technology, Changsha 410114, China

Prof. D. L. Sun, Prof. X. B. Yu

Shanghai Innovation Institute for Materials, Shanghai 200444, China

Keywords: hydrogen storage, borohydrides, magnesium hydride, kinetics, graphene

Due to their ultrahigh theoretical capacity, metal borohydrides are considered to be one of the most promising candidate hydrogen storage materials. Their application still suffers, however, from high operating temperature, sluggish kinetics, and poor reversibility. Designing nanostructures is an effective way of addressing these issues, but seeking suitable approaches remains a big challenge. Here, we report a space-confined solid-gas reaction to synthesize $\operatorname{Mg}\left(\mathrm{BH}_{4}\right)_{2}$ nanoparticles supported on graphene, which serves as the structural support for the dispersed $\mathrm{Mg}\left(\mathrm{BH}_{4}\right)_{2}$ nanoparticles. More notably, density functional theory calculations reveal that graphene could weaken both the $\mathrm{Mg}-\mathrm{H}$ bonds of $\mathrm{MgH}_{2}$ and $\mathrm{B}-\mathrm{B}$ bonds of $\mathrm{B}_{2} \mathrm{H}_{6}$, which could thermodynamically and kinetically facilitate the chemical transformation to synthesize $\operatorname{Mg}\left(\mathrm{BH}_{4}\right)_{2}$ with high purity. Because of the synergistic effects of both the significant reduction in particle size and the catalytic effect of graphene, an onset dehydrogenation temperature of $\sim 154{ }^{\circ} \mathrm{C}$ was observed for $\mathrm{Mg}\left(\mathrm{BH}_{4}\right)_{2}$ nanoparticles, and a complete dehydrogenation could be achieved at a temperature as low as $225^{\circ} \mathrm{C}$, with the 


\section{WILEY-VCH}

formation of $\mathrm{MgB}_{2}$ as the by-product. This work provides a new perspective to tailoring the thermodynamics and kinetics of chemical reactions towards the favorable synthesis of functional inorganic materials.

\section{Introduction}

Hydrogen has great potential to become an ideal energy carrier in the future, due to its abundance, high energy density, and environmental friendliness, but it requires a safe and efficient hydrogen storage technique for its extensive application. ${ }^{[1,2]}$ Storing hydrogen in a solid-state medium is considered to be the safest and most effective way to achieve the widespread application of hydrogen in the future. ${ }^{[3-6]}$ Owing to their high theoretical gravimetric and volumetric capacity for hydrogen, light metal borohydrides, such as $\mathrm{LiBH}_{4}$, $\mathrm{Mg}\left(\mathrm{BH}_{4}\right)_{2}$, and $\mathrm{NaBH}_{4}$, have great potential to be applied as practical hydrogen storage materials. ${ }^{[6-9]}$ Among them, $\mathrm{Mg}\left(\mathrm{BH}_{4}\right)_{2}$ possesses an attractive gravimetric capacity of 14.9 wt. $\%$ and the highest volumetric capacity of $145-147 \mathrm{~kg} / \mathrm{m}^{3} \cdot{ }^{[10]}$ More importantly, due to the much higher Pauling electronegativity $\left(\chi_{\mathrm{p}}\right)$ of $\mathrm{Mg}\left(\chi_{\mathrm{p}}=1.31\right)$ compared to $\mathrm{Ca}, \mathrm{Li}$, and $\mathrm{Na}\left(\chi_{\mathrm{p}}=\right.$ $1.00,0.98$, and 0.93 , respectively), which leads to weaker ionic bonding strength and hence lower stability relative to these borohydrides, $\mathrm{Mg}\left(\mathrm{BH}_{4}\right)_{2}$ exhibits the lowest temperature for hydrogen desorption among all the light metal borohydrides. ${ }^{[1,12]}$ The hydrogen storage process in $\mathrm{Mg}\left(\mathrm{BH}_{4}\right)_{2}$ could be generally described by the following Equation (1): ${ }^{[13]}$

$$
\operatorname{Mg}\left(\mathrm{BH}_{4}\right)_{2} \leftrightarrow \mathrm{MgB}_{2}+4 \mathrm{H}_{2}
$$

Based on the above equation, thermodynamic calculations reveal an enthalpy change of -39 $\mathrm{kJ} \mathrm{mol}^{-1} \mathrm{H}_{2}$ for the dehydrogenation from $\mathrm{Mg}\left(\mathrm{BH}_{4}\right)_{2}$, enabling the hydrogen storage to occur within the temperature range of $20-75^{\circ} \mathrm{C}$, which satisfies the practical requirements for proton exchange membrane fuel cells (PEMFCs). ${ }^{[14,15]}$ Nevertheless, the operating temperature for the dehydrogenation from $\mathrm{Mg}\left(\mathrm{BH}_{4}\right)_{2}$ is generally over $300{ }^{\circ} \mathrm{C}$ owing to its high kinetic barriers, which is mainly attributed to the sluggish diffusion of hydrogen and mass transport 


\section{WILEY-VCH}

towards hydrogen desorption. ${ }^{[16,}$ 17] Furthermore, the formation of stable intermediates generated from multi-step reactions in the dehydrogenation significantly obstructs the reversibility of $\mathrm{Mg}\left(\mathrm{BH}_{4}\right)_{2}$, and hence, only negligible reversibility is observed from its dehydrogenated products, even under harsh conditions, including high hydrogen pressure and high temperature (e.g., $90 \mathrm{MPa}, 400{ }^{\circ} \mathrm{C}$ ), ${ }^{[18]}$ which is regarded as one of the major obstacles for the practical application of $\mathrm{Mg}\left(\mathrm{BH}_{4}\right)_{2}$ for on-board hydrogen storage systems.

To date, the main strategies to improve the hydrogen storage performance of $\operatorname{Mg}\left(\mathrm{BH}_{4}\right)_{2}$ involves the addition of catalysts and reduction of the particle size of $\operatorname{Mg}\left(\mathrm{BH}_{4}\right)_{2}$. Although the adoption of catalysts could indeed modify the kinetics of $\mathrm{Mg}\left(\mathrm{BH}_{4}\right)_{2}$ to some extent, the improvement is very much limited by the density of active sites and the selectivity, accessibility, and stability of the catalyst, as well as the sluggish mass transport and the formation of stable intermediates arising from the dehydrogenation process. ${ }^{[19-24]}$ On the other hand, reduction of the particle size down to nanometer range could directly reduce the barrier of reaction pathways for both hydrogen diffusion and mass transport in the solid state, which would play an important role in relieving the kinetic constraints, and hence, could effectively enhance the dehydrogenation and hydrogenation kinetics. ${ }^{[25-27]}$ In addition, nanostructuring of metal borohydrides could generate large specific surface area, grain boundaries, defects, and increased concentrations of steps, kinks, and corner atoms, which could thermodynamically destabilize the borohydrides towards enhanced hydrogen storage performance. ${ }^{[28,29]}$

Confining or anchoring active materials inside porous hosts is an effective way to synthesize $\mathrm{Mg}\left(\mathrm{BH}_{4}\right)_{2}$ nanoparticles (NPs) by virtue of the structural support of scaffolds. ${ }^{[30-32]}$ Solution impregnation and solid-gas reactions between nanoconfined $\mathrm{MgH}_{2} \mathrm{NPs}$ and diborane $\left(\mathrm{B}_{2} \mathrm{H}_{6}\right)$, according to the Equation (2), are common strategies to incorporate $\mathrm{Mg}\left(\mathrm{BH}_{4}\right)_{2}$ into porous support materials. ${ }^{[33-37]}$ Nevertheless, some unresolved issues significantly hinder the utilization of these strategies to fabricate nanostructured $\mathrm{Mg}\left(\mathrm{BH}_{4}\right)_{2}$ with high density and purity. In terms of the solution impregnation method, the tedious infiltration process and the 


\section{WILEY-VCH}

tremendous decrease in systematic storage capacity due to the introduction of a large amount of inactive scaffolds for hydrogen storage (more than $55 \mathrm{wt} \%$ in general) significantly limits its practical application. ${ }^{[36,38]}$ In addition, irregular spatial distribution and the agglomeration of $\mathrm{Mg}\left(\mathrm{BH}_{4}\right)_{2} \mathrm{NPs}$ are usually observed due to the lack of control over the infiltration process, which would significantly attenuate the effects of space confinement towards improving the performance of $\mathrm{Mg}\left(\mathrm{BH}_{4}\right)_{2} \cdot{ }^{[37]}$ More importantly, the favorable adsorption of $\mathrm{Mg}\left(\mathrm{BH}_{4}\right)_{2}$ from its solvent would not only significantly reduce the purity of the resultant $\mathrm{Mg}\left(\mathrm{BH}_{4}\right)_{2} \mathrm{NPs}$, but also contaminate the released hydrogen upon thermal treatment. ${ }^{[37]}$ Alternatively, although the synthesis of $\mathrm{Mg}\left(\mathrm{BH}_{4}\right)_{2} \mathrm{NPs}$ through the solid-gas reaction between $\mathrm{B}_{2} \mathrm{H}_{6}$ and the nanoconfined $\mathrm{MgH}_{2}$ NPs suffers from almost the same drawbacks as the nanoconfinement of $\mathrm{Mg}\left(\mathrm{BH}_{4}\right)_{2}$ via solution infiltration caused by the nanoconfinement of $\mathrm{MgH}_{2} \mathrm{NPs}$, the presence of organic solvent would be avoided owing to its relatively weak interaction with $\mathrm{MgH}_{2}$. The simultaneous formation of $\mathrm{MgB}_{12} \mathrm{H}_{12}$ with high thermodynamic stability during the solid-gas reaction, however, significantly decreases the purity of the as-synthesized $\mathrm{Mg}\left(\mathrm{BH}_{4}\right)_{2} \mathrm{NPs}$ and the releasable capacity of the whole system. ${ }^{27,} 28$ Therefore, developing a new chemical synthesis strategy to fabricate homogeneous $\mathrm{Mg}\left(\mathrm{BH}_{4}\right)_{2}$ NPs with both high purity and high density is still a big challenge, but it is of particular importance for further improvement of the hydrogen storage performance of $\mathrm{Mg}\left(\mathrm{BH}_{4}\right)_{2}$ towards practical applications.

$$
\mathrm{MgH}_{2}+\mathrm{B}_{2} \mathrm{H}_{6} \rightarrow \mathrm{Mg}\left(\mathrm{BH}_{4}\right)_{2}
$$

To address all the above issues, we present a graphene-tailored solid-gas reaction strategy to fabricate uniform $\mathrm{Mg}\left(\mathrm{BH}_{4}\right)_{2}$ NPs homogeneously distributed on graphene, which plays a vital role in thermodynamically and kinetically enhancing the chemical reaction between $\mathrm{MgH}_{2} \quad \mathrm{NPs}$ and $\mathrm{B}_{2} \mathrm{H}_{6}$ to synthesize borohydrides. Specifically, graphene-supported homogeneous $\mathrm{MgH}_{2} \mathrm{NPs}$ (denoted as $\mathrm{MH}-\mathrm{Gr}$ ) with an average particle size of $\sim 8 \mathrm{~nm}$ were synthesized through a bottom-up self-assembly strategy as in "smart" nanoreactors (Figure 1). Subsequently, a space-confined solid-gas reaction between $\mathrm{B}_{2} \mathrm{H}_{6}$ and graphene-supported 


\section{WILEY-VCH}

$\mathrm{MgH}_{2} \mathrm{NPs}$ under the protection of hydrogen was developed to realize the synthesis of $\mathrm{Mg}\left(\mathrm{BH}_{4}\right)_{2} \mathrm{NPs}$ that are uniformly anchored on graphene (denoted as $\mathrm{MBH}-\mathrm{Gr}$ ) with high loading amount and purity. First, the reduction of the particle size of $\mathrm{MgH}_{2} \mathrm{NPs}$ down to $\sim 8$ $\mathrm{nm}$ significantly decreases the mass transport distance for the solid-gas reaction, which could kinetically promote the formation of $\mathrm{Mg}\left(\mathrm{BH}_{4}\right)_{2}$ from $\mathrm{MgH}_{2}$. More importantly, density functional theory (DFT) calculations demonstrate that the presence of graphene could not only weaken the B-B bonds of $\mathrm{B}_{2} \mathrm{H}_{6}$ and the $\mathrm{Mg}-\mathrm{H}$ bonds of $\mathrm{MgH}_{2}$, but also stabilize the formation of $\mathrm{Mg}\left(\mathrm{BH}_{4}\right)_{2}$, so that it therefore thermodynamically enhances the solid-gas reaction to synthesize $\mathrm{Mg}\left(\mathrm{BH}_{4}\right)_{2}$ NPs. In addition, the nanoreactor composed of $\mathrm{MgH}_{2} \mathrm{NPs}$ and graphene exhibits porous and large interspace structure, which provides facile pathways for the transport of $\mathrm{B}_{2} \mathrm{H}_{6}$ and facilitates sufficient and uniform contact between $\mathrm{MgH}_{2} \mathrm{NPs}$ and $\mathrm{B}_{2} \mathrm{H}_{6}$, promoting the formation of $\mathrm{Mg}\left(\mathrm{BH}_{4}\right)_{2}$ NPs. Moreover, the uniform distribution of $\mathrm{MgH}_{2}$ on graphene with a large interparticle distance through the bottom-up self-assembly approach could guide the formation of homogeneous $\mathrm{Mg}\left(\mathrm{BH}_{4}\right)_{2}$ NPs with high loading, which results in high hydrogen storage capacity and energy density of the whole system. As a result, the as-synthesized $\mathrm{MBH}-\mathrm{Gr}$ exhibits unique structural and hydrogen storage properties, including stable structural integrity, fast hydrogen desorption, low activation barriers, and remarkable reversible hydrogen storage performance.

\section{Results and Discussion}

Graphene-supported homogeneous $\mathrm{MgH}_{2}$ NPs were first synthesized through the hydrogenation-induced solvethermal reaction of dibutyl magnesium. ${ }^{[39]}$ Owing to the favorable adsorption of both dibutyl magnesium and $\mathrm{MgH}_{2}$ on graphene, large amounts of $\mathrm{MgH}_{2}$ NPs are observed to be uniformly dispersed on graphene with a rippled paper-like morphology (Figure 2a), with an absence of unattached nanoparticles. The cross-sectional scanning electron microscope (SEM) image reveals the layer-by-layer stacking of graphene, leading to the formation of porous structure with massive out-of-plane macropores (Figure 


\section{WILEY-VCH}

2b). The uniform distribution of $\mathrm{MgH}_{2} \mathrm{NPs}$ (Figure 2c), which exhibit an average size of 8 $\mathrm{nm}$ (Figure $\mathrm{S} 1$ in the Supporting Information), was further verified by transmission electron microscopy (TEM). The high-resolution TEM (HRTEM) image of MH-Gr in the inset of Figure 2c clearly shows a $d$-spacing of $1.595 \AA$, corresponding to the (220) planes of $\mathrm{MgH}_{2}$, which demonstrates the formation of $\beta-\mathrm{MgH}_{2}$ and coincides well with the X-ray diffraction (XRD) results (Figure 3a). Moreover, the scanning TEM (STEM) image (Figure 2g) clearly illustrates the homogeneous dispersion of $\mathrm{MgH}_{2}$ NPs with a large interparticle distance between the individual NPs. The corresponding element mapping further demonstrates the uniform distribution of $\mathrm{C}$ and $\mathrm{Mg}$ elements (Figure S2). The large interparticle space on the flexible graphene layers could effectively alleviate aggregation and particle growth during the solid-gas reaction to form $\mathrm{Mg}\left(\mathrm{BH}_{4}\right)_{2}$, and meanwhile, the porous structure of graphene could provide facile pathways for the transportation of $\mathrm{B}_{2} \mathrm{H}_{6}$ to react with each $\mathrm{MgH}_{2} \mathrm{NP}$.

Subsequently, MH-Gr was then adopted as the "smart" nanoreactor to synthesize $\operatorname{Mg}\left(\mathrm{BH}_{4}\right)_{2}$ NPs via the space-confined solid-gas reaction between the $\mathrm{MgH}_{2} \mathrm{NPs}$ and $\mathrm{B}_{2} \mathrm{H}_{6}$ on graphene. The XRD patterns (Figure 3a) exhibit the characteristic peaks belonging to $\mathrm{Mg}\left(\mathrm{BH}_{4}\right)_{2}$, along with the disappearance of $\mathrm{MgH}_{2}$, which demonstrates the successful synthesis of $\mathrm{Mg}\left(\mathrm{BH}_{4}\right)_{2}$ based on the solid-gas reaction between $\mathrm{B}_{2} \mathrm{H}_{6}$ and graphene-supported $\mathrm{MgH}_{2} \mathrm{NPs}$. It should be noed that, although the Fourier-transform infrared (FTIR) spectra further confirm the synthesis of $\mathrm{Mg}\left(\mathrm{BH}_{4}\right)_{2}$ by the presence of its characteristic peaks, a weak peak at $2478 \mathrm{~cm}^{-1}$ is also observed, indicating the simultaneous formation of $\mathrm{MgB}_{12} \mathrm{H}_{12} .{ }^{[40]}$ By comparison, without the presence of graphene, $\mathrm{MgH}_{2}$ could be still observed without the formation of crystalline $\mathrm{Mg}\left(\mathrm{BH}_{4}\right)_{2}$ under the same conditions, based on the reaction between $\mathrm{MgH}_{2} \mathrm{NPs}$ and $\mathrm{B}_{2} \mathrm{H}_{6}$, and meanwhile, a strong peak belonging to $\mathrm{MgB}_{12} \mathrm{H}_{12}$ could be observed in the FTIR spectra (Figure S3), which coincides well with the previous reports. ${ }^{[35,36]}$. This directly confirms the important role of graphene in thermodynamically and kinetically facilitating the generation of $\mathrm{Mg}\left(\mathrm{BH}_{4}\right)_{2}$. In order to elucidate the mechanism underlying the formation of 


\section{WILEY-VCH}

$\mathrm{MgB}_{12} \mathrm{H}_{12}$, first-principles calculations were performed based on the density functional theory (DFT). They reveal that the enthalpy for the reaction between $\mathrm{MgH}_{2}$ and $\mathrm{B}_{2} \mathrm{H}_{6}$ to form $\mathrm{Mg}\left(\mathrm{BH}_{4}\right)_{2}$ is around $-240 \mathrm{~kJ} \mathrm{~mol}^{-1}$, while the value for the formation of $\mathrm{MgB}_{12} \mathrm{H}_{12}$ reaches $295 \mathrm{~kJ} \mathrm{~mol}^{-1}$, which validates the formation of $\mathrm{MgB}_{12} \mathrm{H}_{12}$ from the reaction between $\mathrm{MgH}_{2}$ and $\mathrm{B}_{2} \mathrm{H}_{6}$ through thermal heating, which is energetically favorable compared with the synthesis of $\operatorname{Mg}\left(\mathrm{BH}_{4}\right)_{2}$ (Figure $\mathrm{S} 4$ ). In strong contrast, with the support of graphene, the enthalpy for the formation of $\mathrm{Mg}\left(\mathrm{BH}_{4}\right)_{2}$ decreases to $-308 \mathrm{~kJ} \mathrm{~mol}^{-1}$, approaching that of $\mathrm{MgB}_{12} \mathrm{H}_{12}\left(-320 \mathrm{~kJ} \mathrm{~mol}^{-1}\right)$ under the same conditions, demonstrating that the presence of graphene could thermodynamically facilitate the synthesis of $\operatorname{Mg}\left(\mathrm{BH}_{4}\right)_{2}$. The optimized geometry illustrates that the lengths of the $\mathrm{Mg}-\mathrm{H}$ bonds of $\mathrm{MgH}_{2}$ and the $\mathrm{B}-\mathrm{B}$ bonds of $\mathrm{B}_{2} \mathrm{H}_{6}$ are increased to 1.717 and $1.757 \AA$, respectively, while the $\mathrm{B}$ - $\mathrm{B}$ distance of $\mathrm{Mg}\left(\mathrm{BH}_{4}\right)_{2}$ is decreased to $4.109 \AA$ with the support of graphene (Figures 3e, f). This therefore confirms that graphene could weaken both the $\mathrm{Mg}-\mathrm{H}$ and $\mathrm{B}-\mathrm{B}$ bonds and stabilize the formation of $\operatorname{Mg}\left(\mathrm{BH}_{4}\right)_{2}$, which directly demonstrates that graphene could thermodynamically promote the solid-gas reaction between $\mathrm{MgH}_{2}$ and $\mathrm{B}_{2} \mathrm{H}_{6}$ to synthesize $\mathrm{Mg}\left(\mathrm{BH}_{4}\right)_{2}$.

To fully depress the reaction to form $\mathrm{MgB}_{12} \mathrm{H}_{12}$ and promote the formation of $\mathrm{Mg}\left(\mathrm{BH}_{4}\right)_{2}$, the hydrogen pressure was increased from around 10 atm to 50 atm. It could be clearly observed that, with the increase in the hydrogen pressure, the peak at $2478 \mathrm{~cm}^{-1}$ indexed to $\mathrm{MgB}_{12} \mathrm{H}_{12}$ weakens, indicating that the formation of $\mathrm{MgB}_{12} \mathrm{H}_{12}$ is depressed (Figure 3b). Upon increasing the hydrogen pressure to $50 \mathrm{~atm}$, all the peaks present could be assigned to the characteristic peaks of $\mathrm{Mg}\left(\mathrm{BH}_{4}\right)_{2}$ with the complete disappearance of $\mathrm{MgB}_{12} \mathrm{H}_{12}$, which confirms the formation of $\mathrm{Mg}\left(\mathrm{BH}_{4}\right)_{2}$ with high purity (Figure 3b). SEM and TEM images (Figures $2 \mathrm{~d}$ - f) clearly illustrate the presence of uniform nanoparticles homogeneously distributed on graphene without obvious aggregation, validating the well-preserved nature of the morphology after the solid-gas reaction. This indicates that flexible graphene could effectively prevent the agglomeration of $\mathrm{Mg}\left(\mathrm{BH}_{4}\right)_{2} \mathrm{NPs}$ during thermal treatment. The 


\section{WILEY-VCH}

HRTEM image exhibits some lattice fringes with interplanar spacing of $2.4 \AA$ (inset of Figure 2f), corresponding to the (226) planes of $\mathrm{Mg}\left(\mathrm{BH}_{4}\right)_{2}$, which agrees well with the XRD results (Figure 3a) and further demonstrates the synthesis of $\operatorname{Mg}\left(\mathrm{BH}_{4}\right)_{2}$. Furthermore, the elemental mappings of $\mathrm{Mg}, \mathrm{B}$, and $\mathrm{C}$ coincide well with each other for the as-synthesized $\mathrm{MBH}-\mathrm{Gr}$ (Figure 2g), which provides further evidence for the uniform anchoring of the $\mathrm{Mg}\left(\mathrm{BH}_{4}\right)_{2} \mathrm{NPs}$ on graphene. It is noteworthy that the average particle size of the $\operatorname{Mg}\left(\mathrm{BH}_{4}\right)_{2} \mathrm{NPs}$ on graphene increases slightly to $10 \mathrm{~nm}$ due to the incorporation of the foreign element (B) into the $\mathrm{MgH}_{2}$ NPs (Figure S1b), indirectly corroborating the thorough conversion from $\mathrm{MgH}_{2}$ NPs to $\mathrm{Mg}\left(\mathrm{BH}_{4}\right)_{2}$ NPs. The intimate and uniform contact between both the $\mathrm{MgH}_{2} \mathrm{NPs}$ and the $\mathrm{Mg}\left(\mathrm{BH}_{4}\right)_{2} \mathrm{NPs}$ and the graphene induced by the self-assembly strategy could strengthen the effects of graphene towards tailoring their bonding structures, which could thermodynamically and kinetically improve this chemical transformation. More importantly, the homogeneous distribution of the resultant $\mathrm{Mg}\left(\mathrm{BH}_{4}\right)_{2}$ NPs with a uniform particle size of $10 \mathrm{~nm}$ could significantly shorten the diffusion pathways of hydrogen and hence, improve the H-exchange kinetics of hydrogen desorption and absorption, while graphene could effectively prevent the agglomeration and particle growth of $\mathrm{Mg}\left(\mathrm{BH}_{4}\right)_{2}$ NPs during the hydrogen storage process, which endows the as-synthesized $\mathrm{Mg}\left(\mathrm{BH}_{4}\right)_{2}$ NPs with great potential to achieve advanced hydrogen storage performance.

Figure 4a shows the mass spectroscopy (MS) results for the hydrogen desorption from graphene-supported $\mathrm{Mg}\left(\mathrm{BH}_{4}\right)_{2} \mathrm{NPs}$ in comparison with the ball-milled $\mathrm{Mg}\left(\mathrm{BH}_{4}\right)_{2}$ (BM$\mathrm{Mg}\left(\mathrm{BH}_{4}\right)$ ) and a composite of ball-milled $\mathrm{Mg}\left(\mathrm{BH}_{4}\right)_{2}$ and graphene (BM-MBH-Gr). The hydrogen desorption of pure $\mathrm{Mg}\left(\mathrm{BH}_{4}\right)_{2}$ starts at $\sim 296{ }^{\circ} \mathrm{C}$, with two dehydrogenation peaks at $\sim 336{ }^{\circ} \mathrm{C}$ and $\sim 390{ }^{\circ} \mathrm{C}$, which agrees well with the $\mathrm{TG}$ results and is analogous to what was previously reported. ${ }^{[41]}$ A total dehydrogenation capacity of $\sim 12.85$ wt $\%$ was observed for pure $\operatorname{Mg}\left(\mathrm{BH}_{4}\right)_{2}$, which is slightly lower than the theoretical gravimetric capacity of $\mathrm{Mg}\left(\mathrm{BH}_{4}\right)_{2}$ ( 14.9 wt \%), indicating its incomplete decomposition. This is verified by the XRD patterns 


\section{WILEY-VCH}

(Figure S5) and FTIR spectra (Figure S6), which demonstrate that the dehydrogenation products of pure $\mathrm{Mg}\left(\mathrm{BH}_{4}\right)_{2}$ at $450{ }^{\circ} \mathrm{C}$ are mainly composed of $\mathrm{Mg}, \mathrm{MgB}_{12} \mathrm{H}_{12}$, and amorphous boron, with the absence of $\mathrm{MgB}_{2}$, in good agreement with the literature. ${ }^{[11]}$ The formation of $\mathrm{MgB}_{12} \mathrm{H}_{12}$ and amorphous boron instead of $\mathrm{MgB}_{2}$ would not only decrease the releasable capacity of $\mathrm{Mg}\left(\mathrm{BH}_{4}\right)_{2}$, but also significantly limit the reversibility of the dehydrogenated products due to their high thermodynamic stability. ${ }^{[42]}$ Upon the introduction of graphene into $\mathrm{Mg}\left(\mathrm{BH}_{4}\right)_{2}$, the onset temperature for the dehydrogenation of the $\mathrm{BM}-\mathrm{MBH}-\mathrm{Gr}$ is decreased to $\sim 257{ }^{\circ} \mathrm{C}$, with a peak temperature at $\sim 299{ }^{\circ} \mathrm{C}$, which represents a slight reduction compared with pure $\mathrm{Mg}\left(\mathrm{BH}_{4}\right)_{2}$. It indicates that the presence of graphene could play a catalytic role in the hydrogen desorption process of $\mathrm{Mg}\left(\mathrm{BH}_{4}\right)_{2}$. Unfortunately, similar dehydrogenation products were observed for BM-MBH-Gr as compared with pure $\mathrm{Mg}\left(\mathrm{BH}_{4}\right)_{2}$ (Figures S7 and S8), indicating that the reaction pathways for the dehydrogenation from $\operatorname{Mg}\left(\mathrm{BH}_{4}\right)_{2}$ are unchanged after the mechanical milling with graphene. In strong contrast, the as-synthesized MBH-Gr exhibits a one-step decomposition, with the onset and peak temperature downshifted to $154{ }^{\circ} \mathrm{C}$ and $199{ }^{\circ} \mathrm{C}, 103{ }^{\circ} \mathrm{C}$ and $100{ }^{\circ} \mathrm{C}$ lower than that of the ball-milled composite of $\mathrm{Mg}\left(\mathrm{BH}_{4}\right)_{2}$ and graphene, respectively. The hydrogen desorption of $\mathrm{MBH}-\mathrm{Gr}$ mainly occurs in the temperature range from $154{ }^{\circ} \mathrm{C}$ to $260{ }^{\circ} \mathrm{C}$, while the dehydrogenation of $\mathrm{MH}-\mathrm{Gr}$ is mainly derived from the decomposition in the temperature region from 200 to $280{ }^{\circ} \mathrm{C}$, with a peak temperature at $242{ }^{\circ} \mathrm{C}$ (Figure S9), indirectly confirming the uniform formation of $\mathrm{Mg}\left(\mathrm{BH}_{4}\right)_{2}$ NPs from the solid-gas reaction between graphene-supported $\mathrm{MgH}_{2} \mathrm{NPs}$ and $\mathrm{B}_{2} \mathrm{H}_{6}$, and the absence of $\mathrm{MgH}_{2}$. Furthermore, it is interesting to note that the hydrogen desorption of $\mathrm{MBH}-$ Gr is almost complete before the the start of the dehydrogenation process for both BM-MBHGr and pure $\mathrm{Mg}\left(\mathrm{BH}_{4}\right)_{2}$, which further verifies the significantly enhanced dehydrogenation performance that is attributable to the synergistic effects of both the significant reduction of particle size down to $\sim 10 \mathrm{~nm}$ and the catalytic role of graphene. The complete dehydrogenation of MBH-Gr below $300{ }^{\circ} \mathrm{C}$ could be confirmed by the XRD and FTIR results 


\section{WILEY-VCH}

on the dehydrogenated products, in which only diffraction peaks of $\mathrm{MgB}_{2}$ are present, with the disappearance of $\mathrm{Mg}\left(\mathrm{BH}_{4}\right)_{2}$ (Figures S10 and S11), while the presence of $\mathrm{Mg}\left(\mathrm{BH}_{4}\right)_{2}$ could be clearly observed for both BM-MBH-Gr and pure $\mathrm{Mg}\left(\mathrm{BH}_{4}\right)_{2}$ under the same conditions (Figures S5-S8), which agrees well with the MS results. This provides further evidence of the much superior hydrogen storage performance of $\mathrm{MBH}-\mathrm{Gr}$ compared with pure $\mathrm{Mg}\left(\mathrm{BH}_{4}\right)_{2}$ and the ball-milled composite of $\mathrm{Mg}\left(\mathrm{BH}_{4}\right)_{2}$ and graphene. More importantly, no characteristic peaks assigned to $\mathrm{B}-\mathrm{H}$ bonds were detected for $\mathrm{MBH}-\mathrm{Gr}$ after the dehydrogenation process, indicating the absence of $\mathrm{MgB}_{12} \mathrm{H}_{12}$. It is widely demonstrated that bulk $\mathrm{Mg}\left(\mathrm{BH}_{4}\right)_{2}$ decomposes through a polymerization process with the formation of $\mathrm{MgB}_{12} \mathrm{H}_{12}$ as the main intermediate products $^{[14,43,44]}$ and, with the increase of reaction temperature, all B-containing species could be transformed into $\mathrm{MgB}_{2} \cdot{ }^{[40]}$ In the terms of $\mathrm{MBH}-\mathrm{Gr}$, the tremendous decrease of particle size of $\mathrm{Mg}\left(\mathrm{BH}_{4}\right)_{2}$ could effectively reduce the distance for the diffusion of $\mathrm{Mg}, \mathrm{B}$, and $\mathrm{H}$ in the compound and facilitate the mass transport, which lowers the kinetic barrier of the reaction to form $\mathrm{MgB}_{2}$ with favorable thermodynamics, thus promoting the direct formation of $\mathrm{MgB}_{2}$. These results highlight the important roles of nanostructuring and graphene in optimizing the reaction pathways and hence improving both the thermodynamics and the kinetics of $\mathrm{Mg}\left(\mathrm{BH}_{4}\right)_{2}$ towards advanced hydrogen storage performance.

A hydrogen capacity of $~ 8.96$ wt $\%$ could be achieved for MBH-Gr (Figure 4b), which corresponds to a mass loading of $\sim 60 \%$ for $\mathrm{Mg}\left(\mathrm{BH}_{4}\right)_{2}$ NPs distributed on graphene, considering the complete dehydrogenation of $\mathrm{Mg}\left(\mathrm{BH}_{4}\right)_{2}$ to form $\mathrm{MgB}_{2}$. Such a high loading is much superior to those in the reported results (Table S1), which ensures high systematic energy density and satisfies the requirement for practical applications (Figure 4d). The isothermal dehydrogenation kinetics of $\mathrm{MBH}-\mathrm{Gr}$ were further investigated in comparison with the mechanically milled $\mathrm{Mg}\left(\mathrm{BH}_{4}\right)_{2}$ and the composite of $\mathrm{Mg}\left(\mathrm{BH}_{4}\right)_{2}$ and graphene (Figure $4 \mathrm{c}$ ). Only a negligible amount of hydrogen could be released from either the pure $\operatorname{Mg}\left(\mathrm{BH}_{4}\right)_{2}$ or the BM-MBH-Gr within $80 \mathrm{~min}$ at $175{ }^{\circ} \mathrm{C}$. In strong contrast, the capacity released from $\mathrm{MBH}-$ 


\section{WILEY-VCH}

Gr could approach 5.73 wt.\% under identical conditions. As expected, with an increase in temperature from $175{ }^{\circ} \mathrm{C}$ to $225^{\circ} \mathrm{C}$, the capacity released from $\mathrm{MBH}-\mathrm{Gr}$ increases. In particular, a hydrogen capacity of $\sim 9.04 \mathrm{wt} . \%$ could be rapidly released in a $50 \mathrm{~min}$ period at a temperature as low as $250{ }^{\circ} \mathrm{C}$, which far exceeds the US Department of Energy (DOE) hydrogen storage target in 2017 and the values reported in previous related works (Figure 4d). In order to quantitatively evaluate the significantly enhanced hydrogen desorption kinetics of $\mathrm{MBH}-\mathrm{Gr}$, the apparent activation energy $\left(E_{\mathrm{a}}\right)$ for the dehydrogenation from $\mathrm{MBH}-\mathrm{Gr}$ was determined by combining the Johanson-Mehl-Avrami-Kolmogorov (JMAK) results (Equation S1) with the Arrhenius equation (Equation S2) according to the isothermal hydrogen desorption curves at various temperatures. The $E_{\mathrm{a}}$ value for the desorption of $\mathrm{MBH}-$ Gr is calculated to be $28.96 \mathrm{~kJ} \mathrm{~mol}^{-1}$ (Figure S12), much lower than that for pure $\mathrm{Mg}\left(\mathrm{BH}_{4}\right)_{2}$ $\left(45.9 \mathrm{~kJ} \mathrm{~mol}^{-1}\right){ }^{[38]}$ This provides direct proof of the significant improvement of the hydrogen desorption kinetics for graphene-supported $\mathrm{Mg}\left(\mathrm{BH}_{4}\right)_{2}$ NPs, originating mostly from the shortened distances for mass transport, owing to the tremendous size reduction, and the enhanced catalytic effects due to the homogeneous distribution of $\mathrm{Mg}\left(\mathrm{BH}_{4}\right)_{2} \mathrm{NPs}$ on graphene with intimate contact.

The cycling performance of graphene-supported $\mathrm{Mg}\left(\mathrm{BH}_{4}\right)_{2} \mathrm{NPs}$, which is a critically challenging aspect for their practical application, were further investigated by isothermal hydrogenation and dehydrogenation at $250{ }^{\circ} \mathrm{C}$ using the volumetric method, as compared with the ball-milled composite of $\mathrm{Mg}\left(\mathrm{BH}_{4}\right)_{2}$ and graphene (Figure 5a). It is demonstrated that only a negligible amount of hydrogen is released from either pure $\mathrm{Mg}\left(\mathrm{BH}_{4}\right)_{2}$ or the $\mathrm{BM}-\mathrm{MBH}-\mathrm{Gr}$ after 1 cycle of hydrogenation at $250{ }^{\circ} \mathrm{C}$, indicating their poor reversibility, which should be attributed to the formation of amorphous boron and $\mathrm{MgB}_{12} \mathrm{H}_{12}$ with high thermodynamic stability. By comparison, the hydrogen capacity released from $\mathrm{MBH}-\mathrm{Gr}$ under the same conditions still reaches 4.13 wt.\% and 3.47 wt.\% in the second and third cycles, respectively, 


\section{WILEY-VCH}

suggesting the favorable reversibility of graphene-supported $\mathrm{Mg}\left(\mathrm{BH}_{4}\right)_{2}$ NPs. XRD patterns of $\mathrm{MBH}-\mathrm{Gr}$ after 2 cycles of hydrogenation exhibit much weaker peaks of $\mathrm{MgB}_{2}$ compared with the dehydrogenated products (Figure S10), which implies the partial transformation of $\mathrm{MgB}_{2}$ into amorphous species. Based on the FTIR spectra of MBH-Gr after 2 cycles of hydrogenation, the characteristic peaks indexed to $\mathrm{B}-\mathrm{H}$ bonds of $\mathrm{Mg}\left(\mathrm{BH}_{4}\right)_{2}$ could be clearly observed, with a weak peak belonging to $\mathrm{MgB}_{12} \mathrm{H}_{12}$ (Figure S11). These results demonstrate that the $\mathrm{MgB}_{2}$ was partially converted to amorphous $\mathrm{Mg}\left(\mathrm{BH}_{4}\right)_{2}$ with the formation of a small amount of $\mathrm{MgB}_{12} \mathrm{H}_{12}$, which indicates the successful reversibility of $\mathrm{Mg}\left(\mathrm{BH}_{4}\right)_{2}$ with the support of graphene. The TEM and SEM images (Figures 5b, c) demonstrate that the structure of MBH-Gr is well preserved after 3 cycles of hydrogen storage, and no obvious agglomeration is observed, demonstrating the superior physical stability owing to the intimate contact between $\mathrm{Mg}\left(\mathrm{BH}_{4}\right)_{2}$ NPs and graphene, which contributes to the favorable reversibility of the as-synthesized MBH-Gr to some extent. After 3 cycles of dehydrogenation for MBHGr, the formation of $\mathrm{MgB}_{2}$ could be further verified by the HRTEM image (inset of Figure 5c), which exhibits an interplanar spacing of $0.21 \mathrm{~nm}$, corresponding to the (101) planes of hexagonal $\mathrm{MgB}_{2}$. The corresponding elemental mapping of $\mathrm{Mg}, \mathrm{B}$, and $\mathrm{C}$ (Figure 5d) further demonstrates the uniform distribution of $\mathrm{Mg}\left(\mathrm{BH}_{4}\right)_{2}$ NPs in the composite after thermal cycling for dehydrogenation and hydrogenation. The average particle size of $\mathrm{MgB}_{2}$ is calculated to be $\sim 10.3 \mathrm{~nm}$ (Figure S13), which effectively shortens the diffusion pathways for hydrogen and mass transport with enhanced interfacial reactivity, thus leading to the favorable reaction between $\mathrm{MgB}_{2}$ and hydrogen to regenerate $\mathrm{Mg}\left(\mathrm{BH}_{4}\right)_{2}$. It is interesting to note that, due to this unique structure and the favorable formation of $\mathrm{MgB}_{2}$, a reversible hydrogen capacity of 3.24 wt. $\%$ could still be achieved for MBH-Gr in the $6^{\text {th }}$ cycle, and the kinetics of dehydrogenation is well maintained from the $3^{\text {rd }}$ to $6^{\text {th }}$ cycle. The cycling stability and reversible capacity are advanced compared to some other reported works under the same or 


\section{WILEY-VCH}

more severe conditions (Table S2). ${ }^{[22,23,45]}$ It provides further evidence to the superior cycling stability of graphene-supported $\mathrm{Mg}\left(\mathrm{BH}_{4}\right)_{2} \mathrm{NPs}$.

\section{Conclusion}

In summary, we have developed a graphene-confined solid-gas reaction to fabricate $\mathrm{Mg}\left(\mathrm{BH}_{4}\right)_{2}$ NPs with high purity that are homogeneously anchored on graphene, by virtue of graphene-supported $\mathrm{MgH}_{2}$ NPs functioning as smart nanoreactors. Detailed DFT calculations reveal that the presence of graphene could thermodynamically promote the formation of $\mathrm{Mg}\left(\mathrm{BH}_{4}\right)_{2} \mathrm{NPs}$ via weakening the $\mathrm{Mg}-\mathrm{H}$ bonds of $\mathrm{MgH}_{2}$ and the $\mathrm{B}-\mathrm{B}$ bonds of $\mathrm{B}_{2} \mathrm{H}_{6}$, and stabilizing $\operatorname{Mg}\left(\mathrm{BH}_{4}\right)_{2}$, while the reduction of particle size of $\mathrm{MgH}_{2}$ to $\sim 8 \mathrm{~nm}$ and the porous structure could significantly improve the reaction kinetics due to the shortened diffusion pathways for mass transport and the facile transport of $\mathrm{B}_{2} \mathrm{H}_{6}$ to react with individual $\mathrm{MgH}_{2}$ NPs. In addition, the homogeneous distribution of $\mathrm{MgH}_{2} \mathrm{NPs}$ on the flexible graphene with intimate contact could effectively avoid the growth and aggregation of nanoparticles during chemical transformation, leading to the formation of homogeneous $\mathrm{Mg}\left(\mathrm{BH}_{4}\right)_{2}$ NPs with an average particle size of $\sim 10 \mathrm{~nm}$ anchored on graphene. Due to this unique structure, graphene-supported $\mathrm{Mg}\left(\mathrm{BH}_{4}\right)_{2}$ NPs exhibited an onset dehydrogenation temperature of 154 ${ }^{\circ} \mathrm{C}$ and a hydrogen capacity of $\sim 9.04$ wt.\% at a temperature as low as $225{ }^{\circ} \mathrm{C}$. More importantly, owing to the favorable formation of $\mathrm{MgB}_{2}$ and the reduction of particle size to $10.3 \mathrm{~nm}$, a reversible systematic capacity of $4.13 \mathrm{wt} . \%$ was achieved at $300{ }^{\circ} \mathrm{C}$. This novel strategy provides new insights to improve both the thermodynamics and the kinetics of the chemical reactions to synthesize metal borohydrides for advanced hydrogen storage performance. Moreover, the unique mechanism for the synthesis of metal borohydrides could animate further studies on the mechanisms of interface-enhanced chemical reactions.

\section{Supporting Information}

Supporting Information is available from the Wiley Online Library or from the author. 


\section{WILEY-VCH}

\section{Acknowledgements}

This work was partially supported by the National Science Fund for Distinguished Young Scholars (51625102), National Key Research and Development Program of China (2017YFA0204600), the National Natural Science Foundation of China (51471053), the Science and Technology Commission of Shanghai Municipality (17XD1400700), and a Discovery Early Career Researcher Award (DE170100362). The authors also would like to thank Prof. Dianwu Zhou in Hunan University for the support of the DFT calculations software, and Dr. Tania Silver for critical reading of the manuscript.

Received: ((will be filled in by the editorial staff))

Revised: ((will be filled in by the editorial staff)) Published online: ((will be filled in by the editorial staff))

References

[1] L. Schlapbach, A. Zuttel, Nature 2001, 414, 353.

[2] M. B. Ley, L. H. Jepsen, Y.-S. Lee, Y. W. Cho, J. M. Bellosta von Colbe, M.

Dornheim, M. Rokni, J. O. Jensen, M. Sloth, Y. Filinchuk, J. E. Jørgensen, F. Besenbacher, T. R. Jensen, Mater. Today 2014, 17, 122.

[3] Y. Liu, Y. Yang, M. Gao, H. Pan, Chem. Rec. 2016, 16, 189.

[4] M. Paskevicius, L. H. Jepsen, P. Schouwink, R. Cerny, D. B. Ravnsbaek, Y. Filinchuk, M. Dornheim, F. Besenbacher, T. R. Jensen, Chem. Soc. Rev. 2017, 46, 1565.

[5] R. Mohtadi, S.-i. Orimo, Nat. Rev. Mater. 2016, 2, 16091.

[6] Q. Lai, M. Paskevicius, D. A. Sheppard, C. E. Buckley, A. W. Thornton, M. R. Hill, Q. Gu, J. Mao, Z. Huang, H. K. Liu, Z. Guo, A. Banerjee, S. Chakraborty, R. Ahuja, K.-F. Aguey-Zinsou, ChemSusChem 2015, 8, 2789.

[7] S.-i. Orimo, Y. Nakamori, J. R. Eliseo, A. Züttel, C. M. Jensen, Chem. Rev. 2007, 107, 4111.

[8] P. Chen, M. Zhu, Mater. Today 2008, 11, 36.

[9] E. Callini, Z. Ö. K. Atakli, B. C. Hauback, S.-i. Orimo, C. Jensen, M. Dornheim, D. Grant, Y. W. Cho, P. Chen, B. Hjörvarsson, P. Jongh, C. Weidenthaler, M. Baricco, M. Paskevicius, T. R. Jensen, M. E. Bowden, T. S. Autrey, A. Züttel, Appl. Phys. A 2016, 122, 1. 


\section{WILEY-VCH}

[10] O. Zavorotynska, A. El-Kharbachi, S. Deledda, B. C. Hauback, Int. J. Hydrogen Energy 2016, 41, 14387.

[11] H. W. Li, K. Kikuchi, Y. Nakamori, N. Ohba, K. Miwa, S. Towata, S. Orimo, Acta Mater. 2008, 56, 1342.

[12] R. J. Newhouse, V. Stavila, S.-J. Hwang, L. E. Klebanoff, J. Z. Zhang, J. Phys. Chem. C 2010, 114, 5224.

[13] N. Hanada, K. Chlopek, C. Frommen, W. Lohstroh, M. Fichtner, J. Mater. Chem. 2008, $18,2611$.

[14] V. Ozolins, E. H. Majzoub, C. Wolverton, Phys. Rev. Lett. 2008, 100, 135501.

[15] V. Ozolins, E. H. Majzoub, C. Wolverton, J. Am. Chem. Soc. 2009, 131, 230.

[16] E. G. Bardají, N. Hanada, O. Zabara, M. Fichtner, Int. J. Hydrogen Energy 2011, 36, 12313.

[17] A. Al-Kukhun, H. T. Hwang, A. Varma, Int. J. Hydrogen Energy 2012, 37, 17671.

[18] G. Severa, E. Ronnebro, C. M. Jensen, Chem. Commun. 2010, 46, 421.

[19] J. Zheng, X. Xiao, L. Zhang, S. Li, H. Ge, L. Chen, J. Mater. Chem. A 2017, 5, 9723.

[20] A. Nale, F. Pendolino, A. Maddalena, P. Colombo, Int. J. Hydrogen Energy 2016, 41, 11225.

[21] L. Zhang, J. Zheng, L. Chen, X. Xiao, T. Qin, Y. Jiang, S. Li, H. Ge, Q. Wang, Int. J. Hydrogen Energy 2015, 40, 14163.

[22] O. Zavorotynska, I. Saldan, S. Hino, T. D. Humphries, S. Deledda, B. C. Hauback, J. Mater. Chem. A 2015, 3, 6592.

[23] I. Saldan, C. Frommen, I. Llamas-Jansa, G. N. Kalantzopoulos, S. Hino, B. Arstad, R. H. Heyn, O. Zavorotynska, S. Deledda, M. H. Sørby, H. Fjellvåg, B. C. Hauback, Int. J. Hydrogen Energy 2015, 40, 12286.

[24] I. Saldan, S. Hino, T. D. Humphries, O. Zavorotynska, M. Chong, C. M. Jensen, S. Deledda, B. C. Hauback, J. Phys. Chem. C 2014, 118, 23376. 


\section{WILEY-VCH}

[25] Y. Pang, Y. Liu, M. Gao, L. Ouyang, J. Liu, H. Wang, M. Zhu, H. Pan, Nat. Commun. 2014, 5, 3519.

[26] Y. Jia, C. Sun, S. Shen, J. Zou, S. S. Mao, X. Yao, Renew. Sust. Energy Rev. 2015, 44, 289.

[27] H. Shao, G. Xin, J. Zheng, X. Li, E. Akiba, Nano Energy 2012, 1, 590.

[28] G. Xia, D. Li, X. Chen, Y. Tan, Z. Tang, Z. Guo, H. Liu, Z. Liu, X. Yu, Adv. Mater. 2013, 25, 6238 .

[29] P. E. de Jongh, P. Adelhelm, ChemSusChem 2010, 3, 1332.

[30] M. Fichtner, Phys. Chem. Chem. Phys. 2011, 13, 21186.

[31] T. K. Nielsen, F. Besenbacher, T. R. Jensen, Nanoscale 2011, 3, 2086.

[32] X. Yu, Z. Tang, D. Sun, L. Ouyang, M. Zhu, Prog. Mater. Sci. 2017, 88, 1.

[33] M. A. Wahab, D. J. Young, A. Karim, S. Fawzia, J. N. Beltramini, Int. J. Hydrogen Energy 2016, 41, 20573.

[34] M. Han, Q. Zhao, Z. Zhu, Y. Hu, Z. Tao, J. Chen, Nanoscale 2015, 7, 18305.

[35] Y. S. Au, Y. Yan, K. P. de Jong, A. Remhof, P. E. de Jongh, J. Phys. Chem. C 2014, $118,20832$.

[36] Y. Yan, Y. S. Au, D. Rentsch, A. Remhof, P. E. de Jongh, A. Zuttel, J. Mater. Chem. A 2013, $1,11177$.

[37] F. Maximilian, Z.-K. Zhirong, H. Jianjiang, R. Arne, W. Peter, Nanotechnology 2009, $20,204029$.

[38] M. A. Wahab, Y. Jia, D. Yang, H. Zhao, X. Yao, J. Mater. Chem. A 2013, 1, 3471.

[39] G. Xia, Y. Tan, X. Chen, D. Sun, Z. Guo, H. Liu, L. Ouyang, M. Zhu, X. Yu, Adv. Mater. 2015, 27, 5981.

[40] Y. Yan, A. Remhof, D. Rentsch, A. Zuttel, Chem. Commun. 2015, 51, 700. 


\section{WILEY-VCH}

[41] W. I. F. David, S. K. Callear, M. O. Jones, P. C. Aeberhard, S. D. Culligan, A. H. Pohl, S. R. Johnson, K. R. Ryan, J. E. Parker, P. P. Edwards, C. J. Nuttall, A. Amieiro-Fonseca, Phys. Chem. Chem. Phys. 2012, 14, 11800.

[42] M. Chong, A. Karkamkar, T. Autrey, S.-i. Orimo, S. Jalisatgi, C. M. Jensen, Chem. Commun. 2011, 47, 1330.

[43] Z. Lu, F. Ciucci, Chem. Mater. 2017, 29, 9308.

[44] Y. Zhang, E. Majzoub, V. Ozoliņ̌̌, C. Wolverton, Phys. Rev. B 2010, 82, 174107.

[45] M. Rueda, L. M. Sanz-Moral, A. Girella, P. Cofrancesco, C. Milanese, Á. Martín, Int. J. Hydrogen Energy 2016, 41, 15245. 


\section{WILEY-VCH}

\section{Self-assembly}

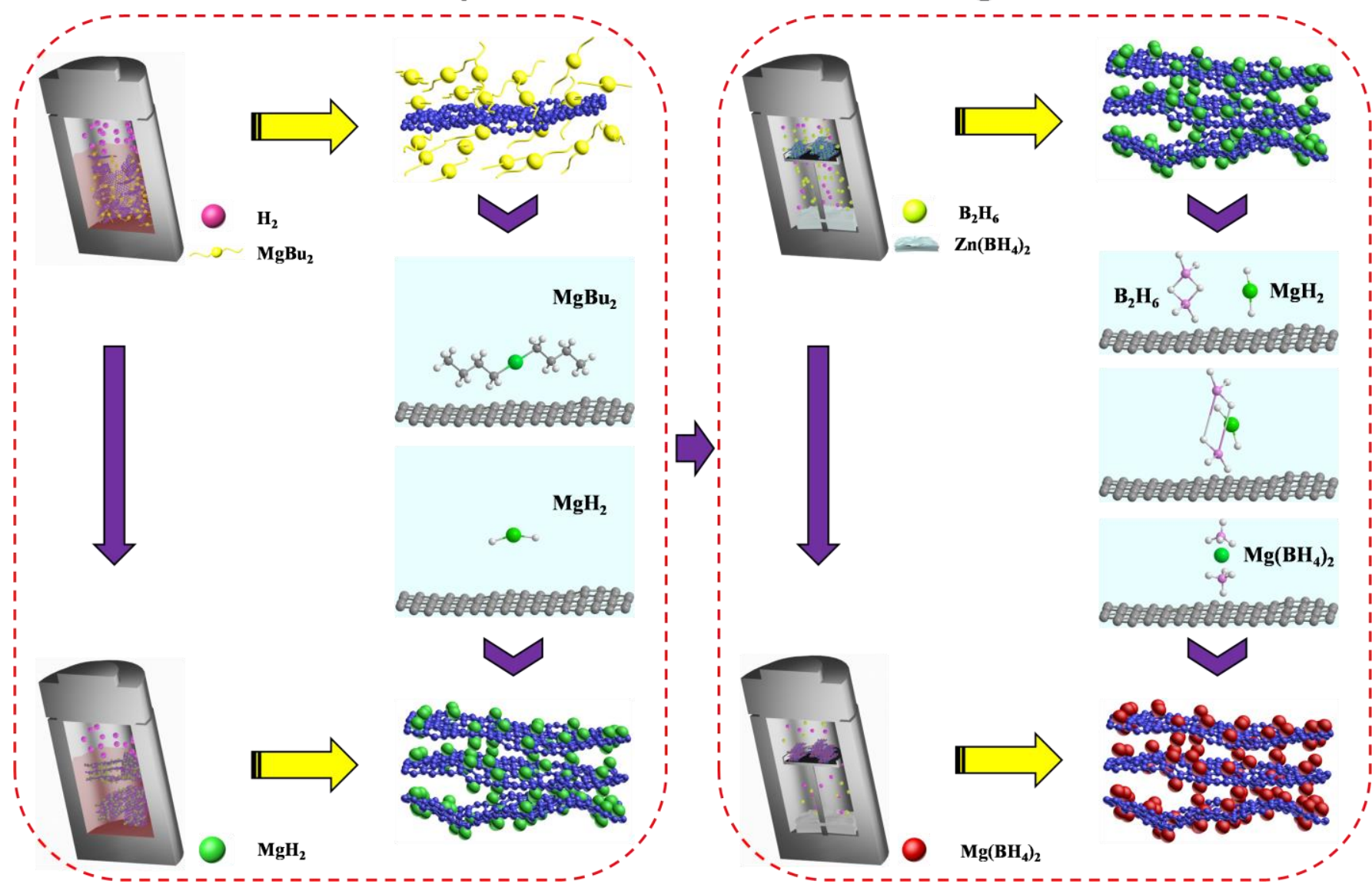

Figure 1. Schematic illustration of the fabrication of MBH-Gr via space-confined solid-gas reaction: (1) Self-assembly of $\mathrm{MgH}_{2} \mathrm{NPs}_{\text {s }}$ graphene (MH-Gr) via a bottom-up solvothermal reaction, serving as the "smart" nanoreactor; (2) the graphene-tailored solid-gas reaction between $\mathrm{MH}-\mathrm{Gr}$ and $\mathrm{B}_{2} \mathrm{H}_{6}$ to synthesize $\mathrm{Mg}\left(\mathrm{BH}_{4}\right)_{2}$ NPs that are uniformly distributed on graphene (MBH-Gr) under the protection of hydrogen. 


\section{WILEY-VCH}

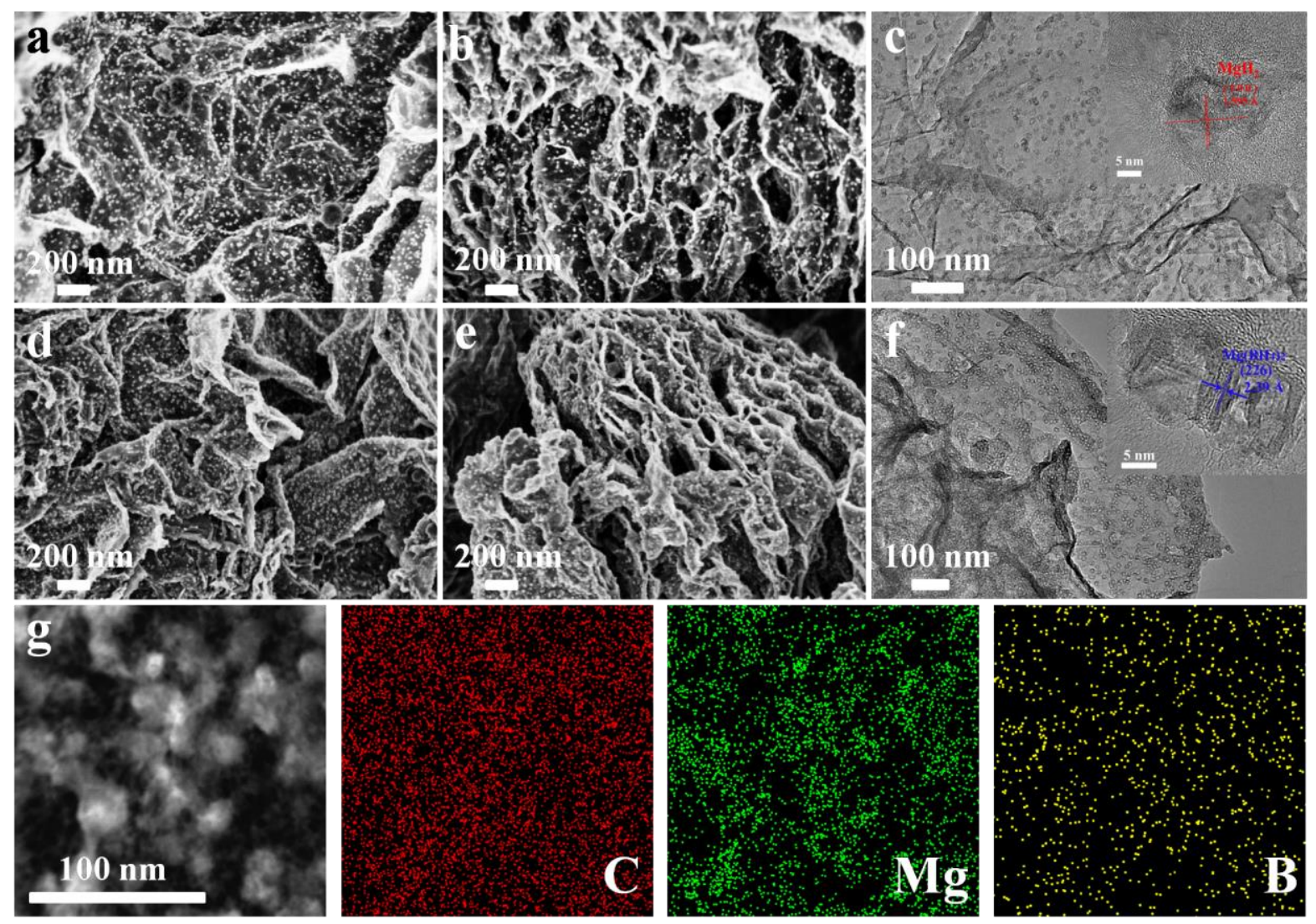

Figure 2. (a) SEM, (b) cross-sectional SEM, and (c) TEM images of MH-Gr. (d) SEM, (e) cross-sectional SEM, and (f) TEM images of MBH-Gr. (g) Representative STEM image and the corresponding elemental mapping of MBH-Gr. The insets of (c, f) exhibit the corresponding HRTEM images of MH-Gr and MBH-Gr, respectively. 
WILEY-VCH
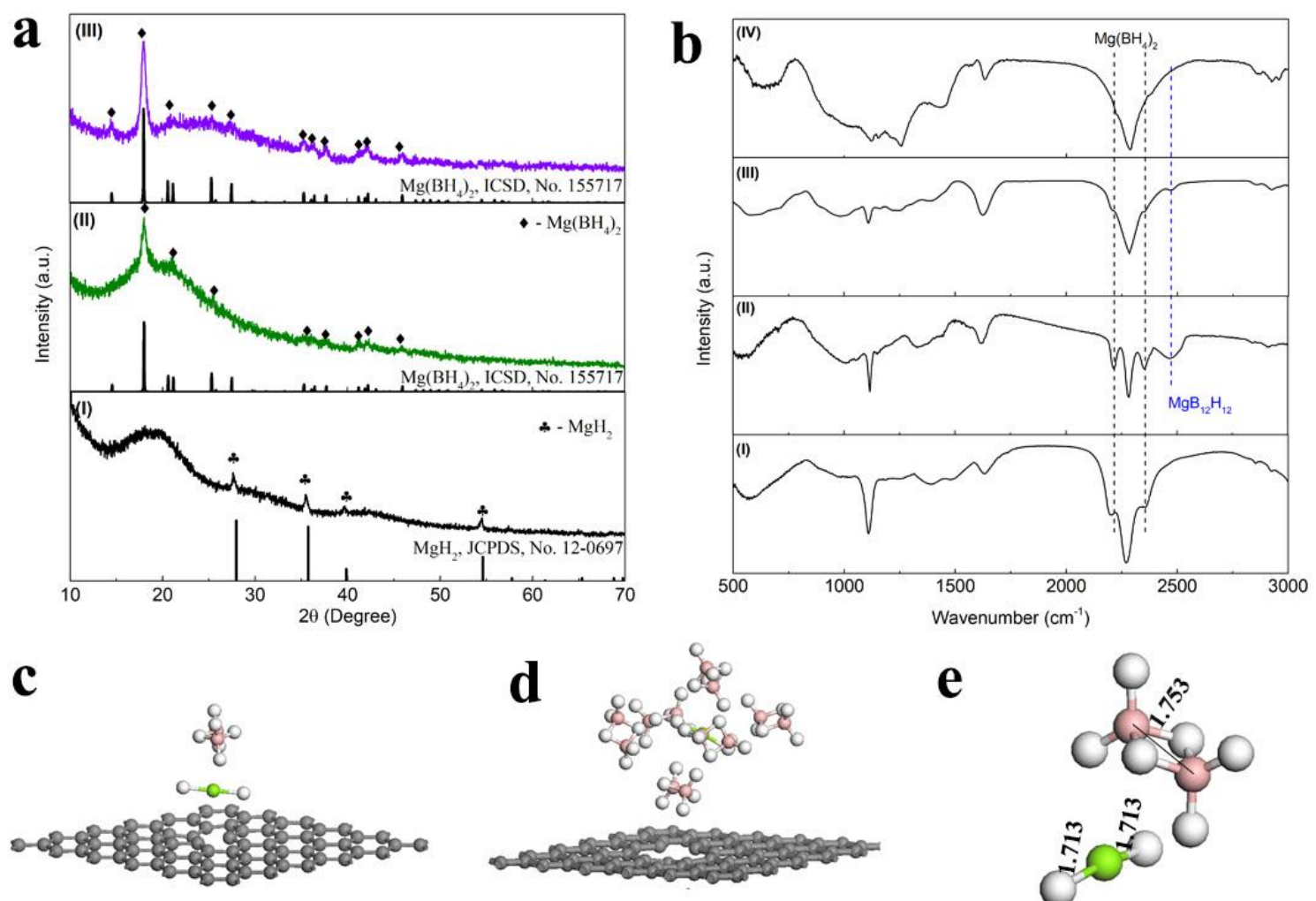

e
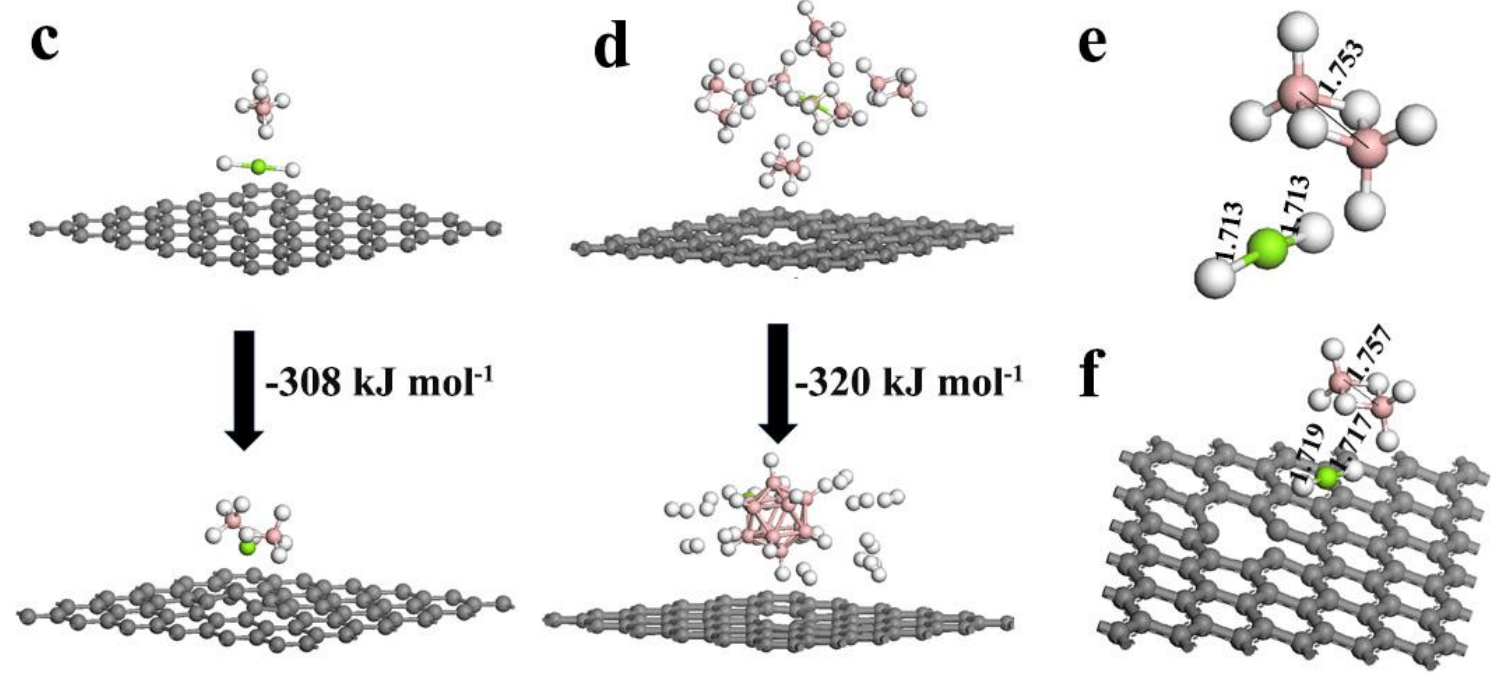

Figure 3. (a) XRD patterns of (I) $\mathrm{MH}-\mathrm{Gr}$ and $\mathrm{MBH}-\mathrm{Gr}$ synthesized under hydrogen pressure of (II) $10 \mathrm{~atm}$ and (III) $50 \mathrm{~atm}$, respectively. (b) FTIR spectra of MBH-Gr synthesized under hydrogen pressure of (II) $10 \mathrm{~atm}$, (III) $20 \mathrm{~atm}$, and (IV) $50 \mathrm{~atm}$, respectively, including pure $\mathrm{Mg}\left(\mathrm{BH}_{4}\right)_{2}$ (I) for comparison. Relaxed atomic configurations of $\mathrm{MgH}_{2}$ and $\mathrm{B}_{2} \mathrm{H}_{6}$, and calculated reaction enthalpies for the formation of (c) $\mathrm{Mg}\left(\mathrm{BH}_{4}\right)_{2}$ and (d) $\mathrm{MgB}_{12} \mathrm{H}_{12}$ from the reaction between $\mathrm{MgH}_{2}$ and $\mathrm{B}_{2} \mathrm{H}_{6}$ with the support of graphene. Relaxed atomic configurations of $\mathrm{MgH}_{2}$ and $\mathrm{B}_{2} \mathrm{H}_{6}$ without (e) and with (f) the support of graphene. Grey, white, green, and pink spheres are $\mathrm{C}, \mathrm{H}, \mathrm{Mg}$, and $\mathrm{B}$ atoms, respectively. 


\section{WILEY-VCH}
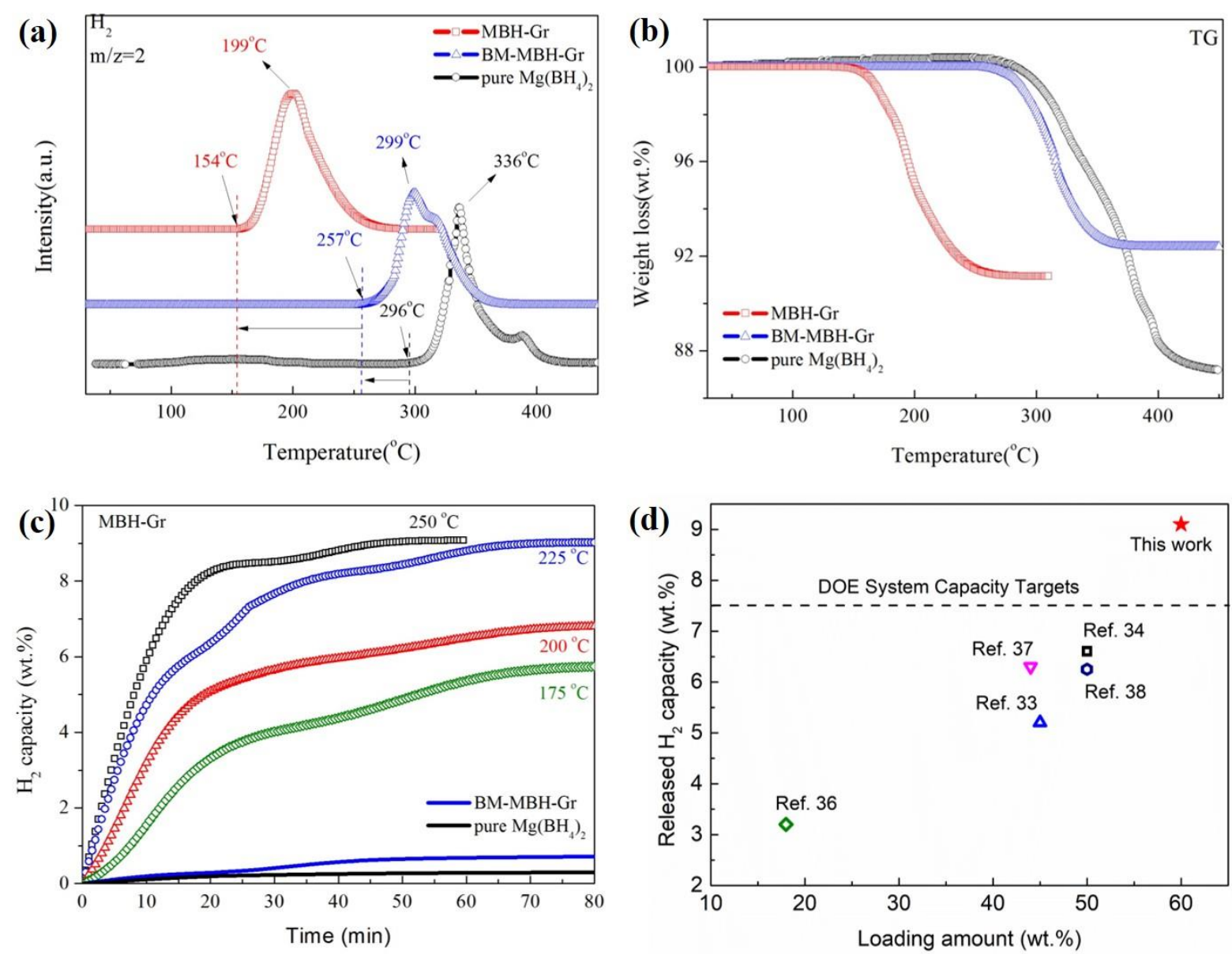

Figure 4. (a) Mass spectra and (b) thermogravimetric analysis curves of the as-synthesized $\mathrm{MBH}-\mathrm{Gr}$ compared with $\mathrm{BM}-\mathrm{MBH}-\mathrm{Gr}$ and pure $\mathrm{Mg}\left(\mathrm{BH}_{4}\right)_{2}$. (c) Isothermal dehydrogenation of the as-synthesized $\mathrm{MBH}-\mathrm{Gr}$ at various temperatures, with $\mathrm{BM}-\mathrm{MBH}-\mathrm{Gr}$ and pure $\mathrm{Mg}\left(\mathrm{BH}_{4}\right)_{2}$ at $175{ }^{\circ} \mathrm{C}$ included for comparison. (d) Systematic comparison of the loading amount and the highest hydrogen capacity that could be released below $250{ }^{\circ} \mathrm{C}$ of $\mathrm{MBH}-\mathrm{Gr}$ and nanoconfined $\mathrm{Mg}\left(\mathrm{BH}_{4}\right)_{2}$ NPs in the hosts reported in the previous literature (Supplementary Table S1) with our results in the present work. 


\section{WILEY-VCH}

(a)
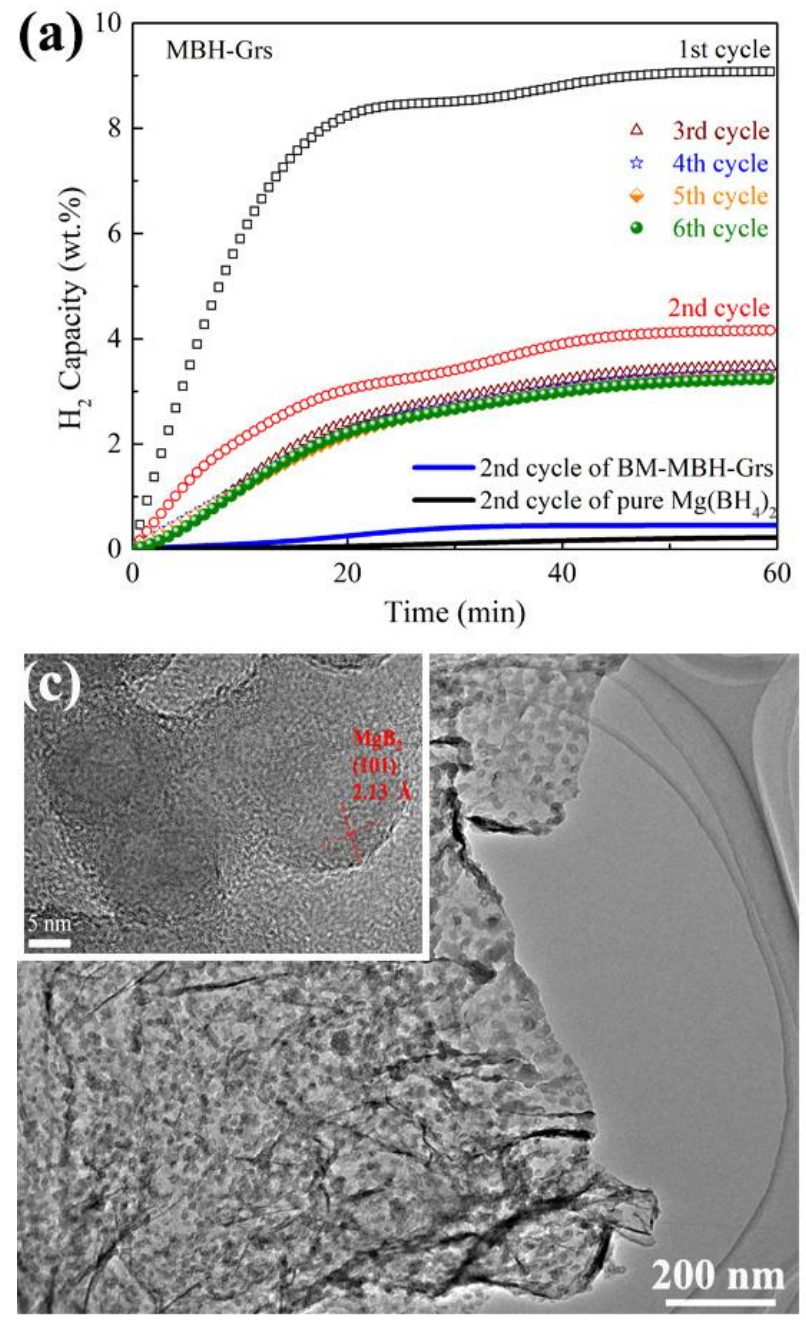
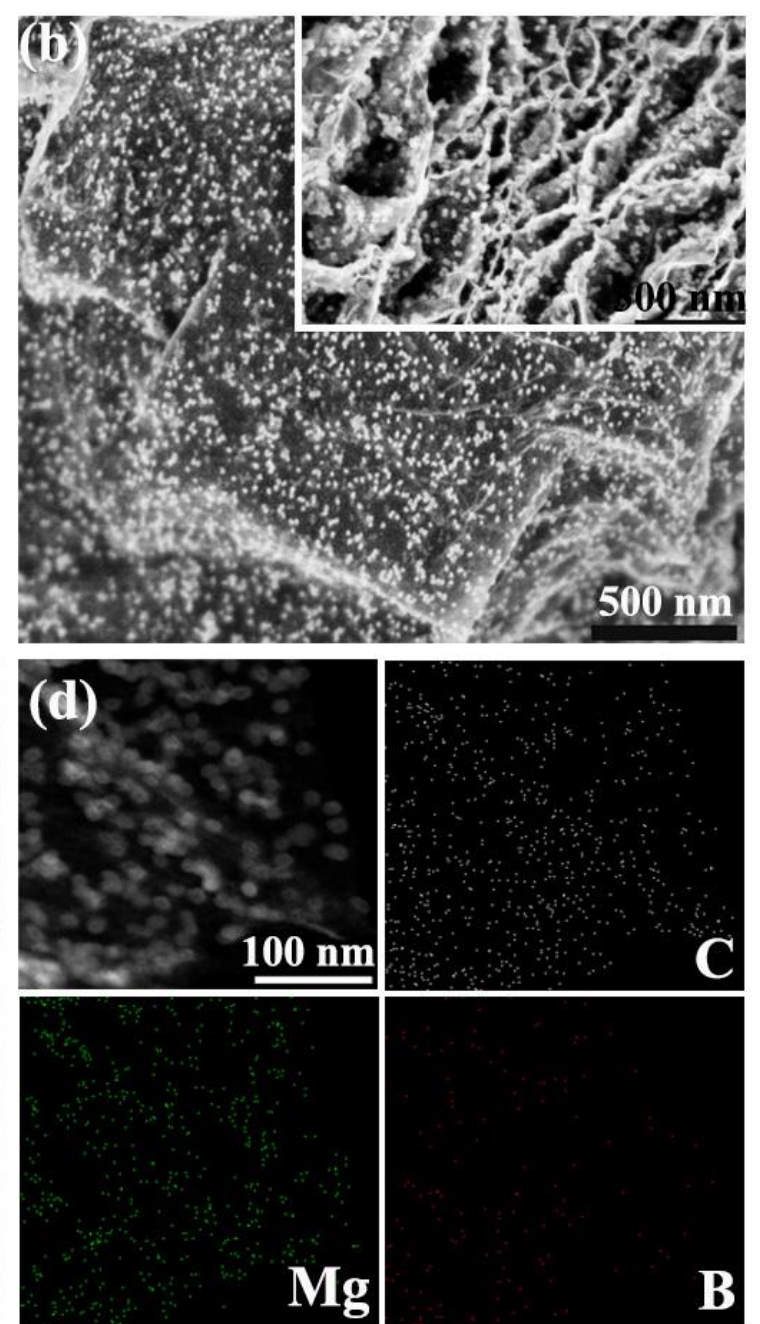

Figure 5. (a) Reversible-dehydrogenation hydrogen storage capacities of MBH-Gr, with BM$\mathrm{MBH}-\mathrm{Gr}$ and pure $\mathrm{Mg}\left(\mathrm{BH}_{4}\right)_{2}$ at $250{ }^{\circ} \mathrm{C}$ included for comparison. (b) SEM and (c) TEM images, and (d) representative STEM image and the corresponding elemental mapping of the as-synthesized $\mathrm{MBH}-\mathrm{Gr}$ after 3 cycles of dehydrogenation and rehydrogenation. The insets of $(b, c)$ exhibit the corresponding cross-sectional SEM and HRTEM images of MH-Gr and MBH-Gr, respectively. 


\section{WILEY-VCH}

A graphene-tailored solid-gas reaction has been designed to synthesize $\operatorname{Mg}\left(\mathrm{BH}_{4}\right)_{2}$ nanoparticles with high purity, in which graphene could weaken both the $\mathrm{Mg}-\mathrm{H}$ bonds of $\mathrm{MgH}_{2}$ and the $\mathrm{B}-\mathrm{B}$ bonds of $\mathrm{B}_{2} \mathrm{H}_{6}$, thermodynamically and kinetically facilitating the reaction to form $\mathrm{Mg}\left(\mathrm{BH}_{4}\right)_{2}$. Because of the reduction in particle size and the catalytic effects of graphene, complete dehydrogenation could be achieved for $\mathrm{Mg}\left(\mathrm{BH}_{4}\right)_{2}$ at $225^{\circ} \mathrm{C}$.

Keyword: hydrogen storage, borohydrides, magnesium hydride, kinetics, graphene

H. Y. Zhang, G. L. Xia, * J. Zhang, D. L. Sun, Z. P. Guo, X. B. Yu*

Graphene-Tailored Thermodynamics and Kinetics to Fabricate Metal Borohydride Nanoparticles with High Purity and Enhanced Reversibility

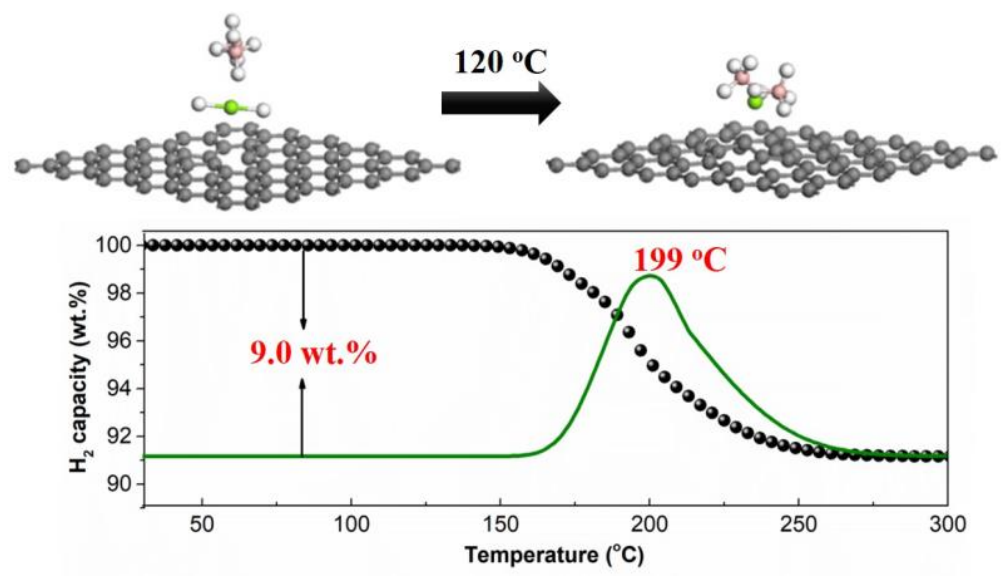




\section{WILEY-VCH}

((Supporting Information can be included here using this template))

Copyright WILEY-VCH Verlag GmbH \& Co. KGaA, 69469 Weinheim, Germany, 2016.

\section{Supporting Information}

\section{Graphene-Tailored Thermodynamics and Kinetics to Fabricate Metal Borohydride Nanoparticles with High Purity and Enhanced Reversibility}

Hongyu Zhang, Guanglin Xia, * Jian Zhang, Dalin Sun, Zaiping Guo, Xuebin Yu*

\section{Experimental section}

All samples were prepared in an argon purified glove box (Mbraun Labmaster) with moisture and oxygen under $0.1 \mathrm{ppm}$.

Synthesis of $M H-G r: \mathrm{MgH}_{2}$ nanoparticles supported by graphene were prepared via the method in our previous report. ${ }^{[\mathrm{S} 1]}$ In a typical synthesis of $\mathrm{MH}-\mathrm{Gr}, 0.042 \mathrm{~g}$ of graphene and $1.6 \mathrm{~mL}$ of dibutyl-magnesium solution (Sigma-Aldrich, $1 \mathrm{M}$ in heptane) were mixed in $40 \mathrm{ml}$ of cyclohexane (Sigma-Aldrich, 99.5\%). The mixture was transferred into a pressure reactor vessel, which was then heated at $200{ }^{\circ} \mathrm{C}$ under a hydrogen pressure of $4.5 \mathrm{MPa}$ for $24 \mathrm{~h}$. After consecutive washing and centrifugation, the composite was dried under dynamic vacuum at $80{ }^{\circ} \mathrm{C}$ on a Schlenk line to obtain $\mathrm{MgH}_{2}$ nanoparticles distributed on graphene.

Synthesis of $\mathrm{MBH}-\mathrm{Gr}$ : MBH-Gr was synthesized by thermal treatment of $0.02 \mathrm{~g}$ of $\mathrm{MH}-\mathrm{Gr}$ under an atmosphere of $\mathrm{B}_{2} \mathrm{H}_{6}$ at $120^{\circ} \mathrm{C}$ for $24 \mathrm{~h}$ in a sealed reactor vessel. The reactor was charged with hydrogen to the targeted pressure. Subsequently, the mixed $\mathrm{B}_{2} \mathrm{H}_{6} / \mathrm{H}_{2}$ gas was obtained through thermally heating a mixture of $\mathrm{ZnCl}_{2}$ (Alfa-Aesar, 98+\%) and $\mathrm{LiBH}_{4}$ (Sigma-Aldrich, $90 \%$ ) with a molar ratio of $1: 2$ at $120^{\circ} \mathrm{C}$, which was placed at the bottom of the reactor. After the reaction between $\mathrm{MH}-\mathrm{Gr}$ and $\mathrm{B}_{2} \mathrm{H}_{6}$, the reactor vessel was degassed under dynamic vacuum at $80{ }^{\circ} \mathrm{C}$ for $12 \mathrm{~h}$ to obtain the $\mathrm{MBH}-\mathrm{Gr}$. 


\section{WILEY-VCH}

Synthesis of BM-MBH-Gr: The BM-MBH-Gr was synthesized by ball milling bulk $\mathrm{Mg}\left(\mathrm{BH}_{4}\right)_{2}$ and graphene in a gravimetric ratio of 3:2 at $300 \mathrm{rpm}$ for $2 \mathrm{~h}$ using a planetary QM-1SP2. The weight ratio between the bulk $\mathrm{Mg}\left(\mathrm{BH}_{4}\right)_{2}$ and graphene was determined by the loading amount of $\mathrm{Mg}\left(\mathrm{BH}_{4}\right)_{2}$ in the as-synthesized MBH-Gr.

Characterization and testing: X-ray diffraction (XRD) was performed on a D8 Advance from the Bruker AXS corporation with $\mathrm{Cu} \mathrm{K} \alpha$ radiation $(\lambda=1.5418 \AA)$ to verify the phase composition. The samples were covered with amorphous tape to prevent contact with air during the XRD measurements. Fourier transform infrared (FTIR) analysis was conducted on a Magna-IR 550 II from the Nicolet corporation. The samples were mixed with $\mathrm{KBr}$ and then loaded into a sealed tube for FTIR measurements. Transmission electron microscopy (TEM; JEOL 2011 F, Tokyo, Japan) and scanning electron microscopy (SEM; JEOL 7500FA, Tokyo, Japan) were used to reveal the morphology of the samples. The particle size distribution and the average particle size of the as-synthesized $\mathrm{Mg}\left(\mathrm{BH}_{4}\right)_{2} \mathrm{NPs}$ were obtained by measuring 100 particles in relative TEM images using the Nano-Measure software. Thermogravimetric analysis (TG; Netzsch STA449 F3) and mass spectroscopy (MS; Hidden HPR 20) were carried out at a heating rate of $5{ }^{\circ} \mathrm{C} \mathrm{min}^{-1}$ under an argon flow of $80 \mathrm{ml} \mathrm{min}{ }^{-1}$. Sieverts' apparatus (GRC, Advanced Materials Corp., USA) was used to investigate the hydrogen storage properties of MBH-Gr. The hydrogen desorption was measured at various temperatures under an initial hydrogen pressure of $0.01 \mathrm{~atm}$, and the reversible hydrogen absorption was conducted at $300{ }^{\circ} \mathrm{C}$ under an initial hydrogen pressure of $100 \mathrm{~atm}$. Calculations of the apparent activation energy: The apparent activation energy $\left(E_{\mathrm{a}}\right)$ of the dehydrogenation from MBH-Gr was determined by combining the Johanson-Mehl-AvramiKolmogorov (JMAK) results (Equation (S1)) with the Arrhenius results (Equation (S2)) according to the isothermal hydrogen desorption curves at different temperatures. ${ }^{[\mathrm{S} 2]}$ According to the JMAK model, the $E_{\mathrm{a}}$ can be approximately described as follows:

$$
\ln [-\ln (1-\alpha)]=\eta \ln t+\eta \ln k
$$




\section{WILEY-VCH}

where $\alpha$ is the fraction of dehydrogenation from $\mathrm{Mg}\left(\mathrm{BH}_{4}\right)_{2}$ at time $t, k$ is an effective kinetic parameter, and $\eta$ is the Avrami exponent, which is related to the transformation mechanism.

Based on the values of $k$ at various temperatures, the $E_{\mathrm{a}}$ for the composite could be obtained from the Arrhenius equation as shown below:

$$
k=A \exp \left(-E_{\mathrm{a}} / R T\right)
$$

Where $A$ is a temperature-independent coefficient, $R$ is the universal gas constant, and $T$ is the absolute temperature.

Theoretical calculations: The calculations were performed based on the density functional theory (DFT) approach ${ }^{[\mathrm{S} 3]}$ using the $\mathrm{DMol}^{3}$ package. The effects of exchange correlation interaction were treated according to Perdew-Wang generalized-gradient approximation (GGA-PW91). ${ }^{[\text {S4] }}$ All-electron Kohn-Sham wave functions were expanded in a double numerical basis with polarized orbital (DNP). ${ }^{[\mathrm{S} 5]}$ Sampling of the irreducible wedge of Brillouin zone was performed with a regular Monkhorst-Pack grid of special k-points. ${ }^{[\mathrm{S} 6]}$ The convergence criteria for relaxation were $1.0 \times 10^{-5} \mathrm{Ha}, 0.002 \mathrm{Ha} / \AA$, and $0.005 \AA$ for the energy, gradient, and atomic displacement, respectively. The reaction enthalpies for the formation of $\mathrm{Mg}\left(\mathrm{BH}_{4}\right)_{2}$ and $\mathrm{MgB}_{12} \mathrm{H}_{12}$ from the reaction between $\mathrm{MgH}_{2}$ and $\mathrm{B}_{2} \mathrm{H}_{6}$ without or with the support of graphene were calculated according to the reaction equations of $\mathrm{MgH}_{2}+$ $\mathrm{B}_{2} \mathrm{H}_{6}=\mathrm{Mg}\left(\mathrm{BH}_{4}\right)_{2}(\mathrm{~S} 3)$ and $\mathrm{MgH}_{2}+6 \mathrm{~B}_{2} \mathrm{H}_{6}=\mathrm{MgB}_{12} \mathrm{H}_{12}+13 \mathrm{H}_{2}(\mathrm{~S} 4)$, respectively. First, the composites composed of $\mathrm{MgH}_{2}$ and $\mathrm{B}_{2} \mathrm{H}_{6}$ monomers without or with the support of graphene were fully relaxed and set as the reactants of Eq. (S3) or (S4), respectively. Secondly, one fully relaxed $\mathrm{Mg}\left(\mathrm{BH}_{4}\right)_{2}$ monomer without or with the support of graphene was set as the product of Eq. (S3), while the fully relaxed composite composed of one $\mathrm{MgB}_{12} \mathrm{H}_{12}$ monomer and thirteen $\mathrm{H}_{2}$ molecules was set as the product of Eq. (S4). Based on the difference of the total energies between products and reactants, the reaction enthalpies for the formation of $\operatorname{Mg}\left(\mathrm{BH}_{4}\right)_{2}$ and $\mathrm{MgB}_{12} \mathrm{H}_{12}$ without or with the support of graphene were obtained. 


\section{WILEY-VCH}
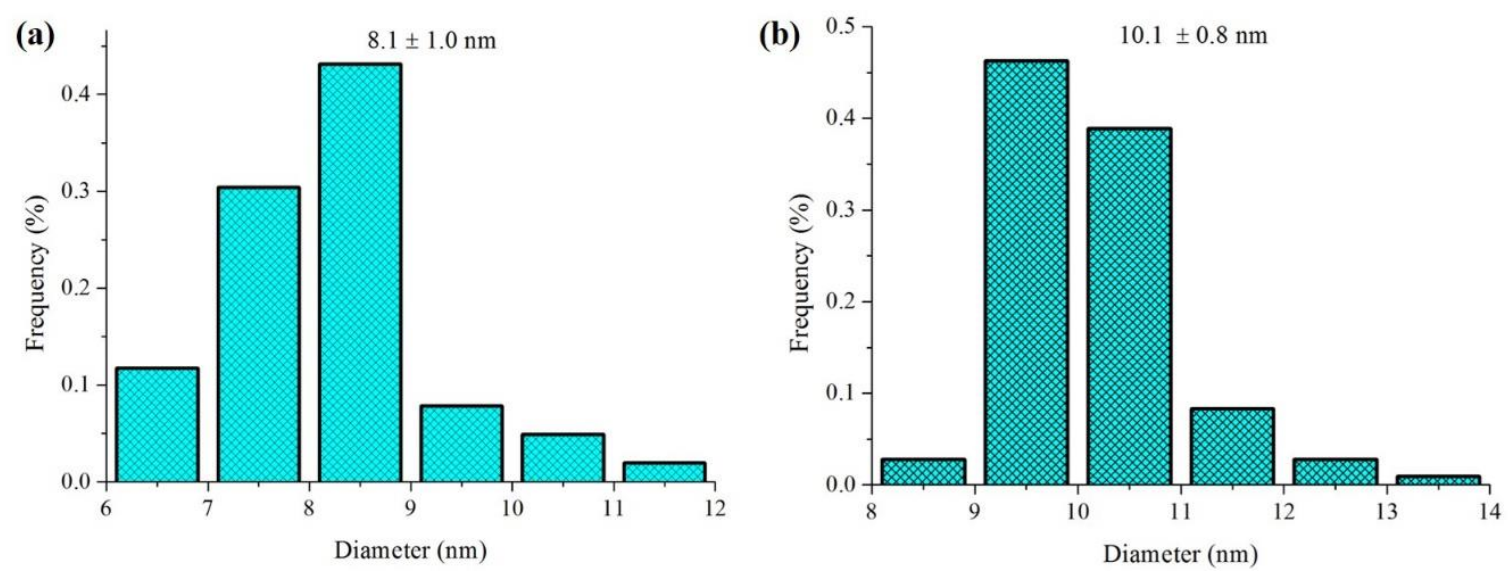

Figure S1. Particle size distribution of (a) the as-synthesized MH-Gr and (b) MBH-Gr.
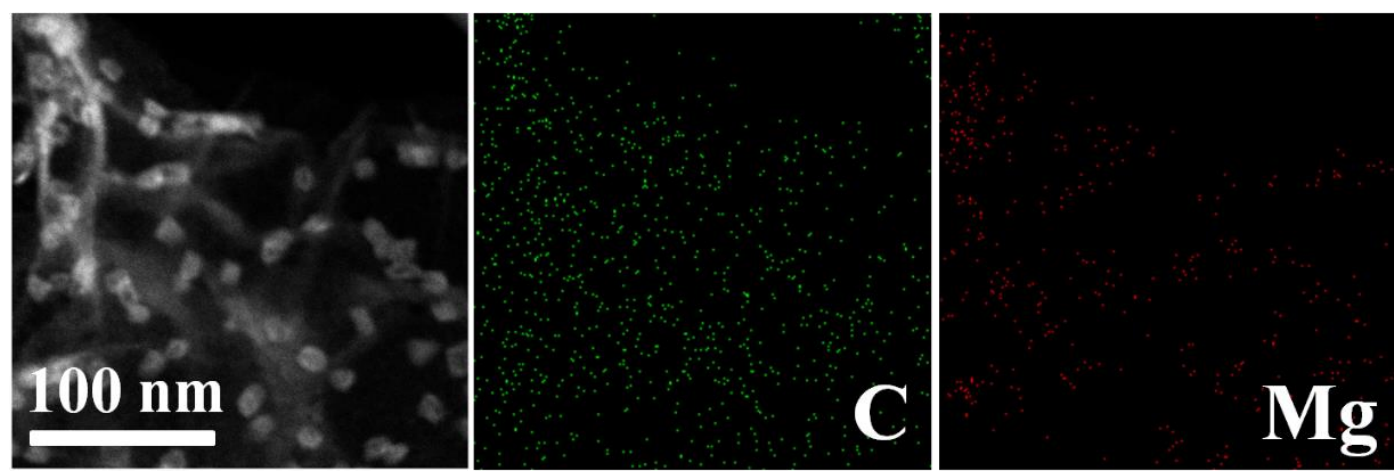

Figure S2. STEM image and the corresponding element mapping of the as-synthesized MH-

Gr. 


\section{WILEY-VCH}
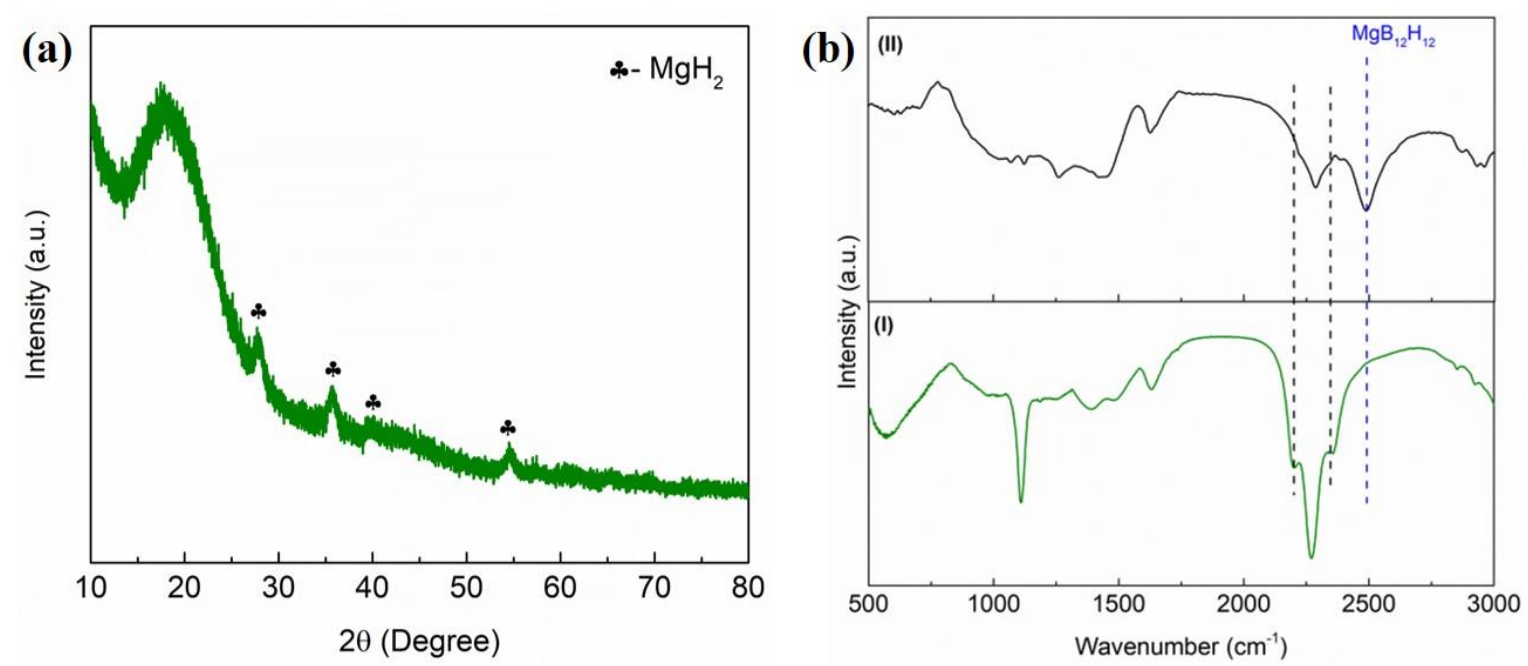

Figure S3. (a) XRD pattern and (b) FTIR spectra of $\mathrm{MgH}_{2}$ NPs (II) after the reaction with $\mathrm{B}_{2} \mathrm{H}_{6}$ under the same conditions but in the absence of graphene, with pure $\mathrm{Mg}\left(\mathrm{BH}_{4}\right)_{2}(\mathrm{I})$ included for comparison. 


\section{WILEY-VCH}

(a)
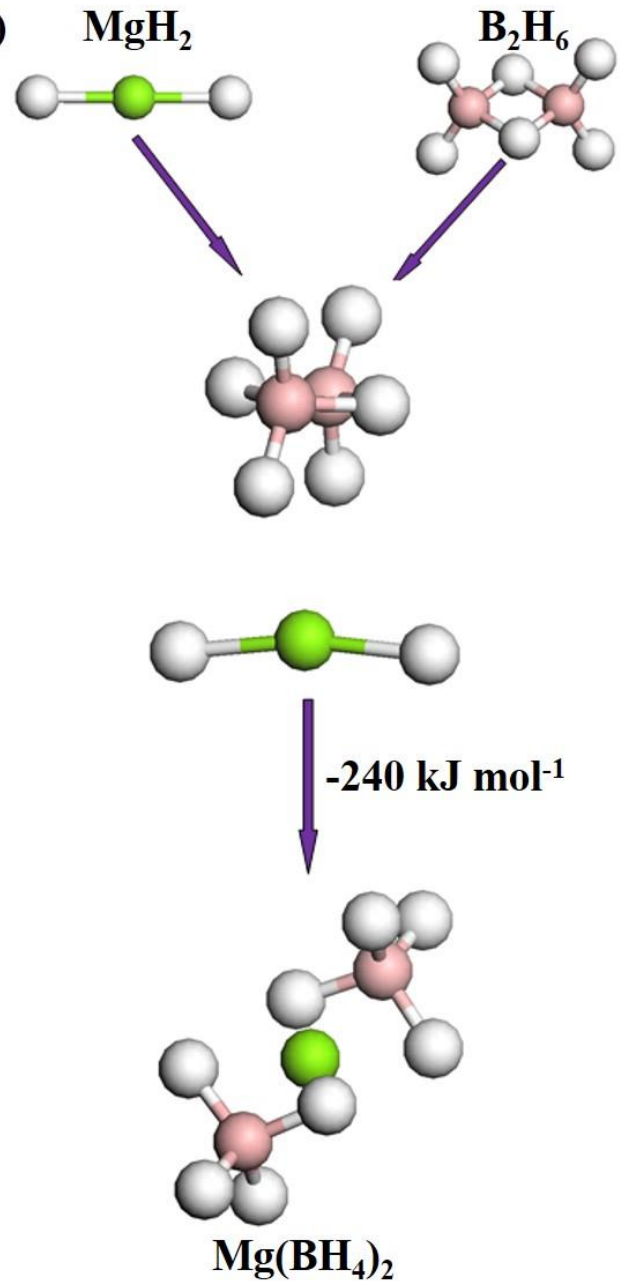

(b)

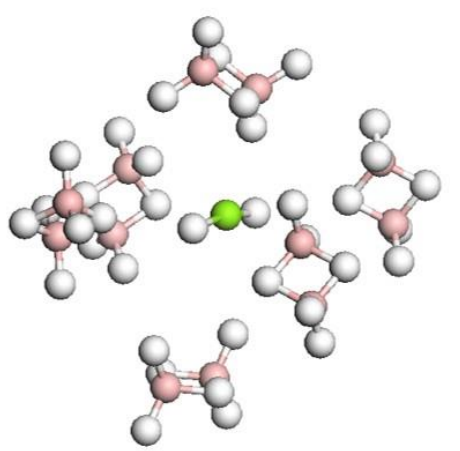

$\mathrm{MgH}_{2}+6 \mathrm{~B}_{2} \mathrm{H}_{6}$

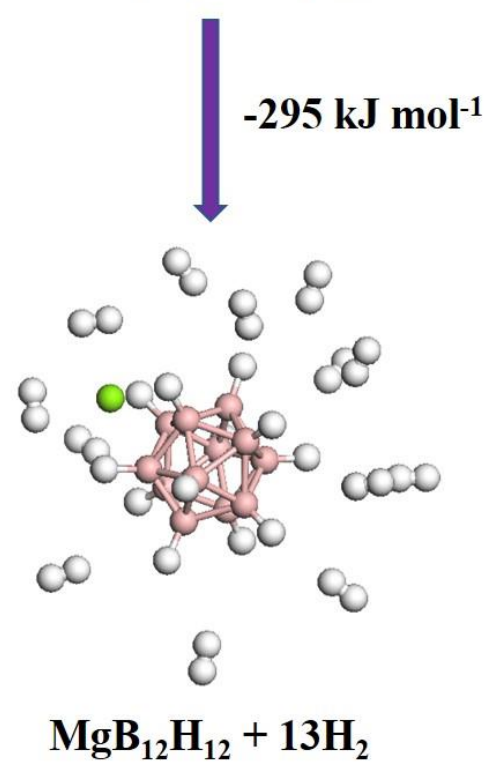

Figure S4. Relaxed atomic configurations of $\mathrm{MgH}_{2}$ and $\mathrm{B}_{2} \mathrm{H}_{6}$, and the calculated reaction enthalpies for the formation of (a) $\mathrm{Mg}\left(\mathrm{BH}_{4}\right)_{2}$ and (b) $\mathrm{MgB}_{12} \mathrm{H}_{12}$ from the reaction between $\mathrm{MgH}_{2}$ and $\mathrm{B}_{2} \mathrm{H}_{6}$ without the support of graphene. White, green, and pink spheres are $\mathrm{H}, \mathrm{Mg}$, and $\mathrm{B}$ atoms, respectively. 


\section{WILEY-VCH}

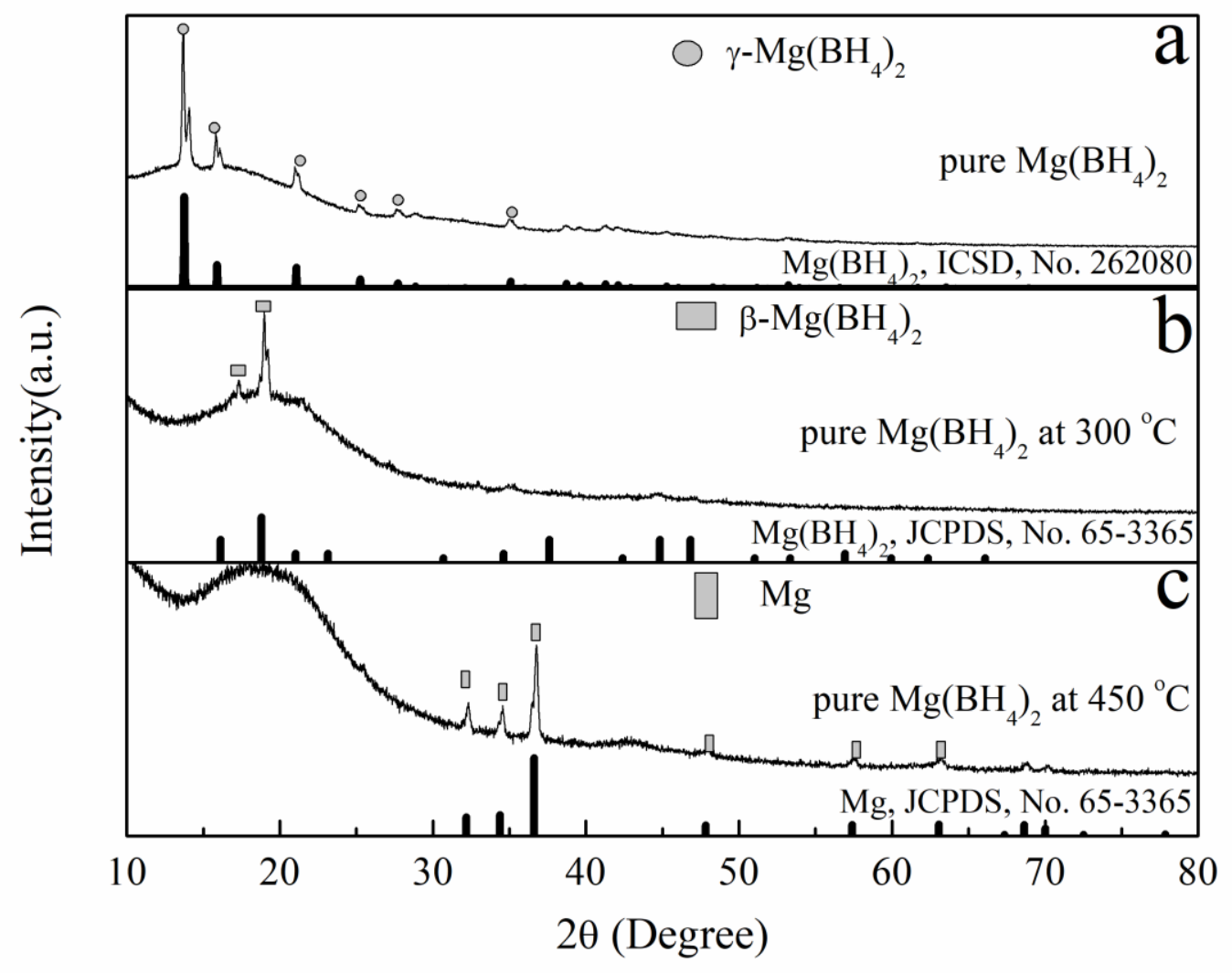

Figure S5. XRD patterns of pure $\operatorname{Mg}\left(\mathrm{BH}_{4}\right)_{2}$ (a), and the dehydrogenated products after heating to $300{ }^{\circ} \mathrm{C}$ (b) and $450{ }^{\circ} \mathrm{C}$ (c). 


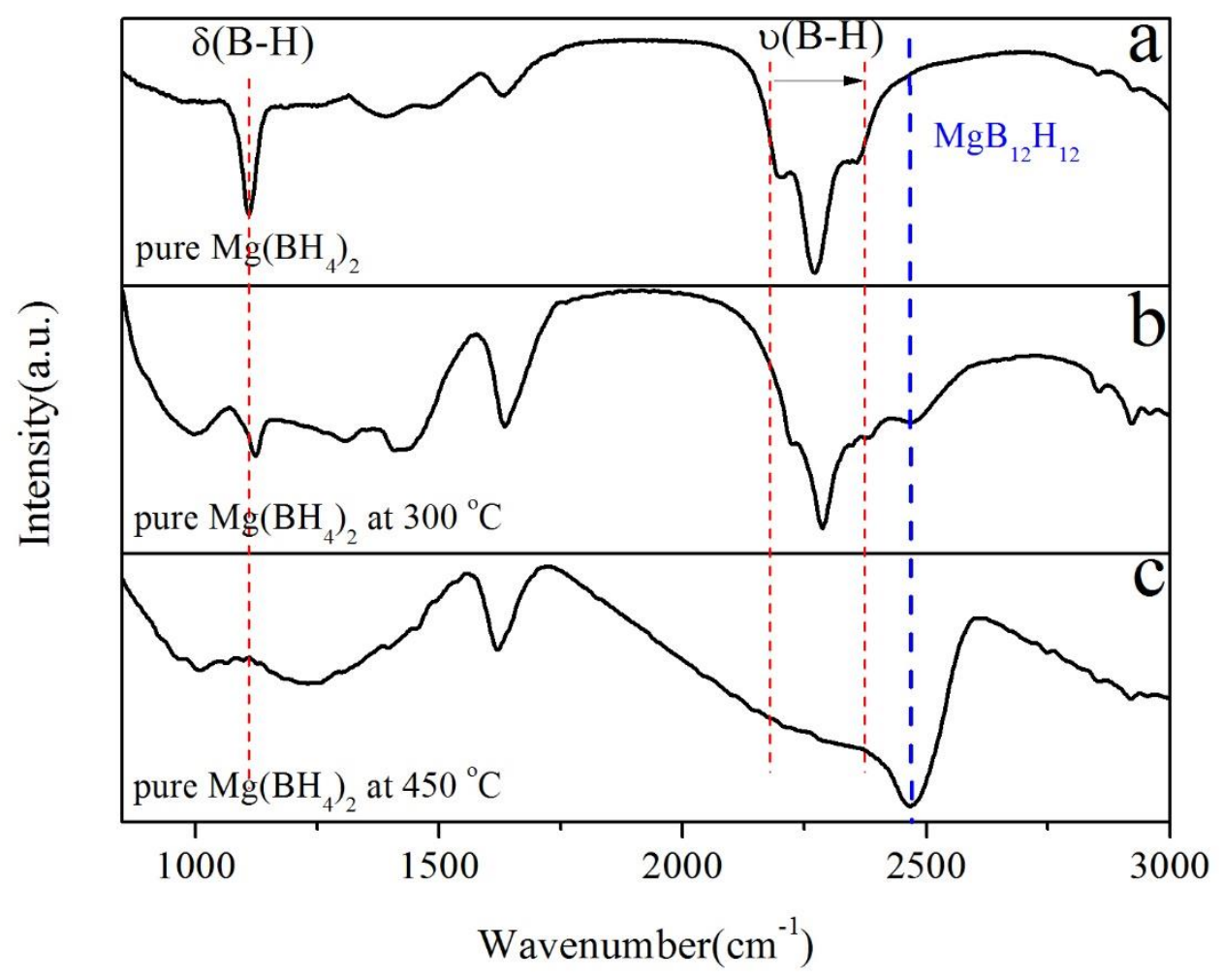

Figure S6. FTIR spectra of pure $\mathrm{Mg}\left(\mathrm{BH}_{4}\right)_{2}$ (a), and the dehydrogenated products after heating to $300{ }^{\circ} \mathrm{C}$ (b) and $450{ }^{\circ} \mathrm{C}$ (c). 


\section{WILEY-VCH}

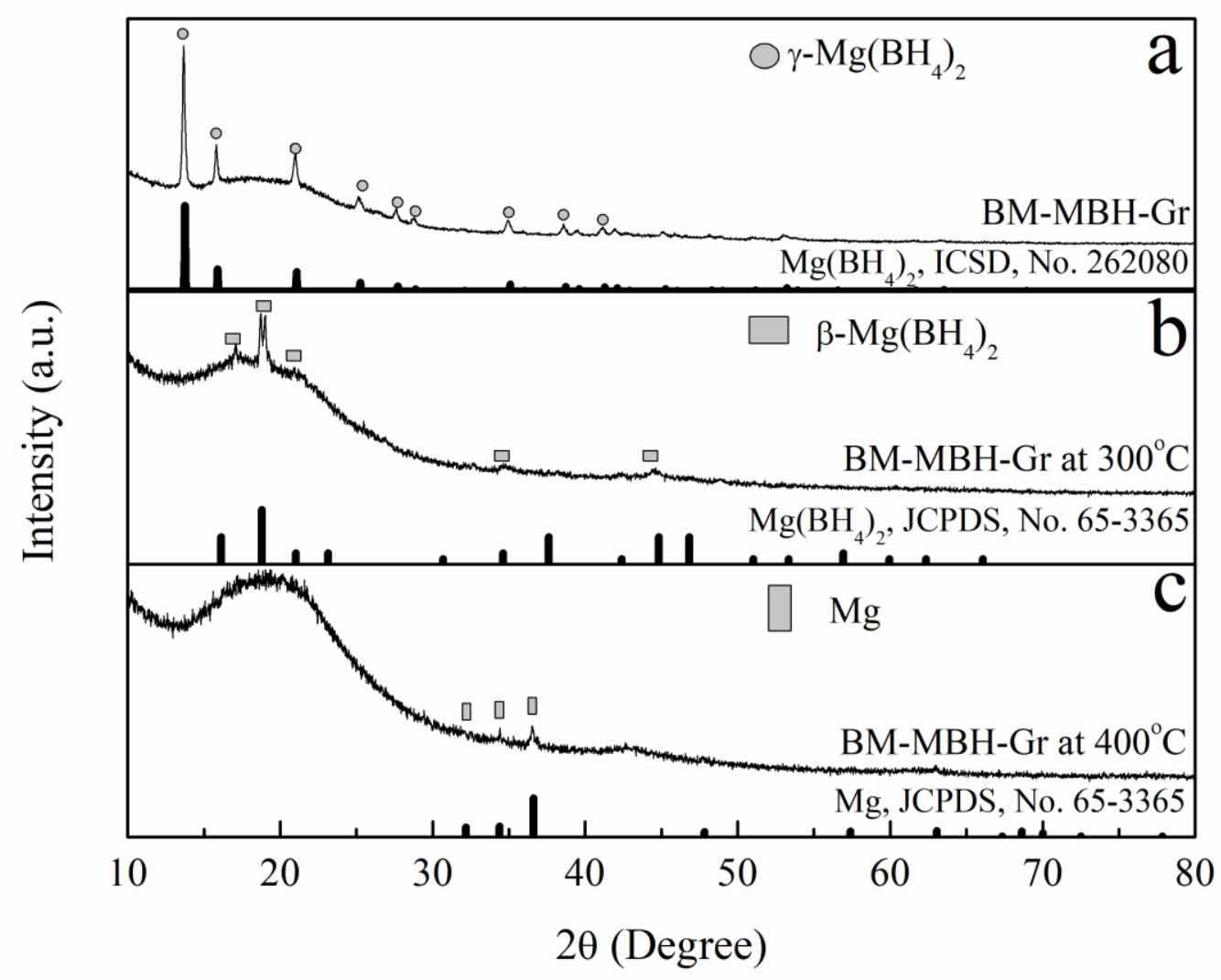

Figure S7. XRD patterns of BM-MBH-Gr (a), and the dehydrogenated products after heating to $300{ }^{\circ} \mathrm{C}(\mathrm{b})$ and $450{ }^{\circ} \mathrm{C}(\mathrm{c})$. 


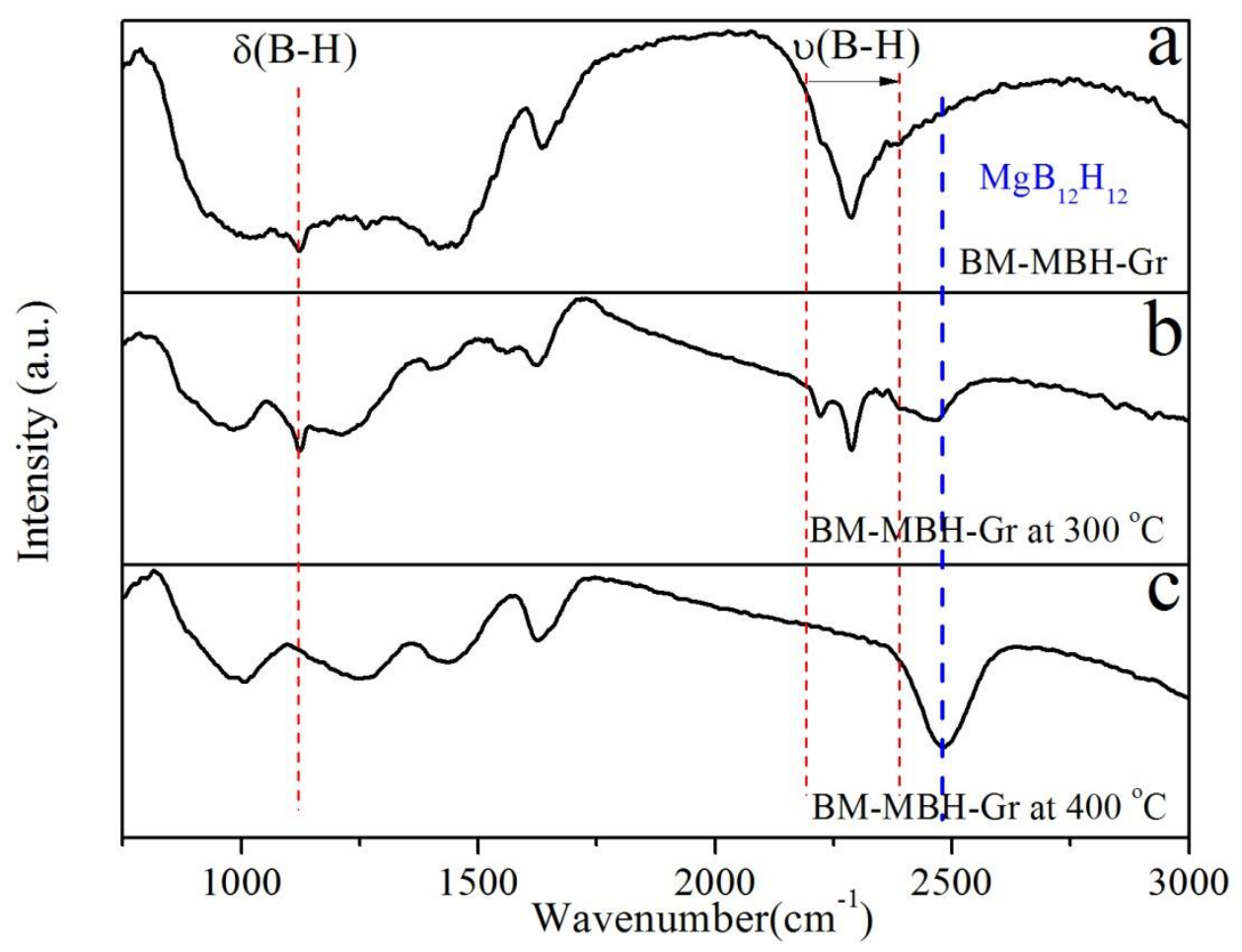

Figure S8. FTIR spectra of BM-MBH-Gr (a), and the dehydrogenated products after heating to $300{ }^{\circ} \mathrm{C}$ (b) and $450{ }^{\circ} \mathrm{C}$ (c). 


\section{WILEY-VCH}

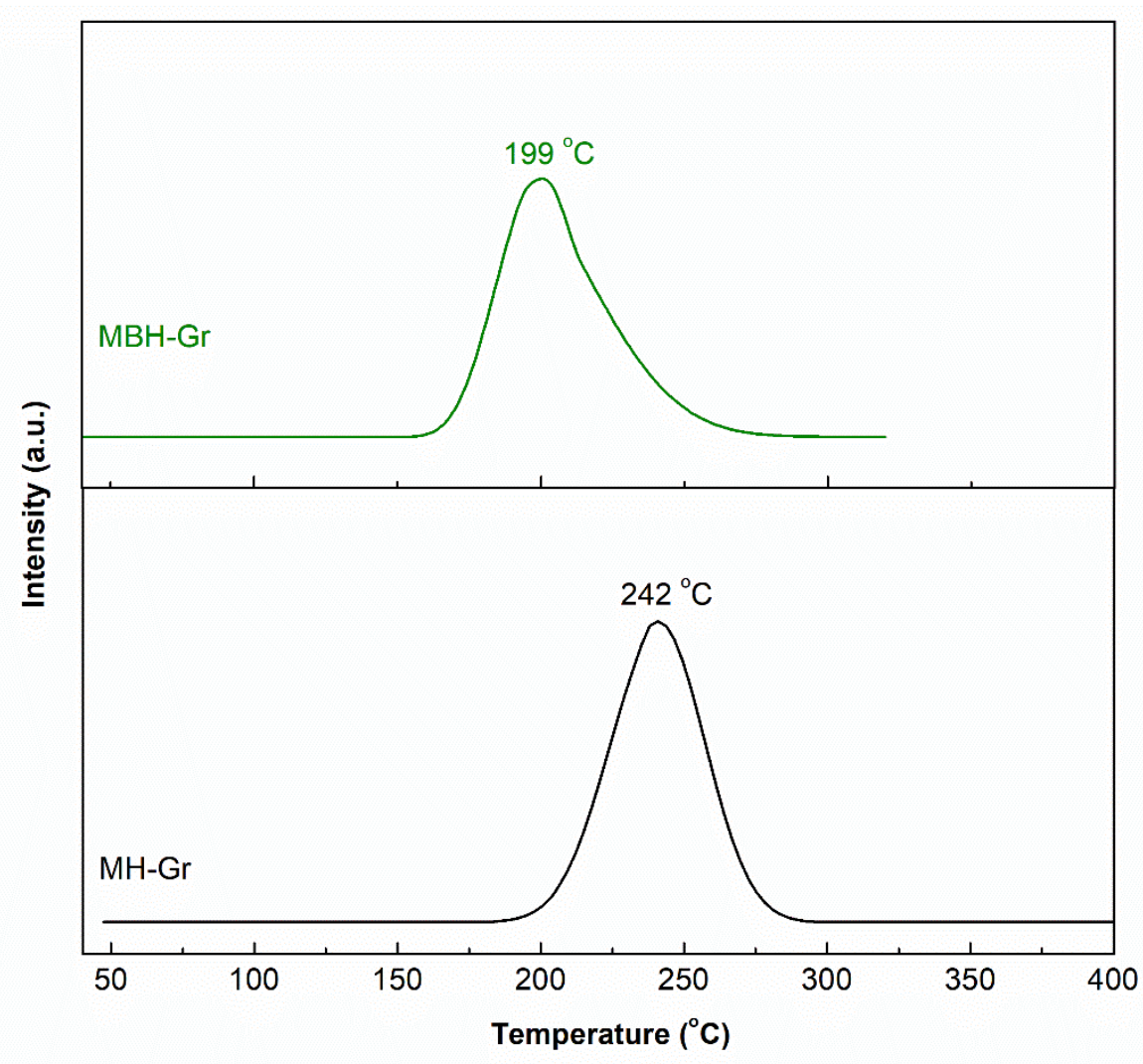

Figure S9. MS spectra of the as-synthesized MBH-Gr and MH-Gr. 


\section{WILEY-VCH}

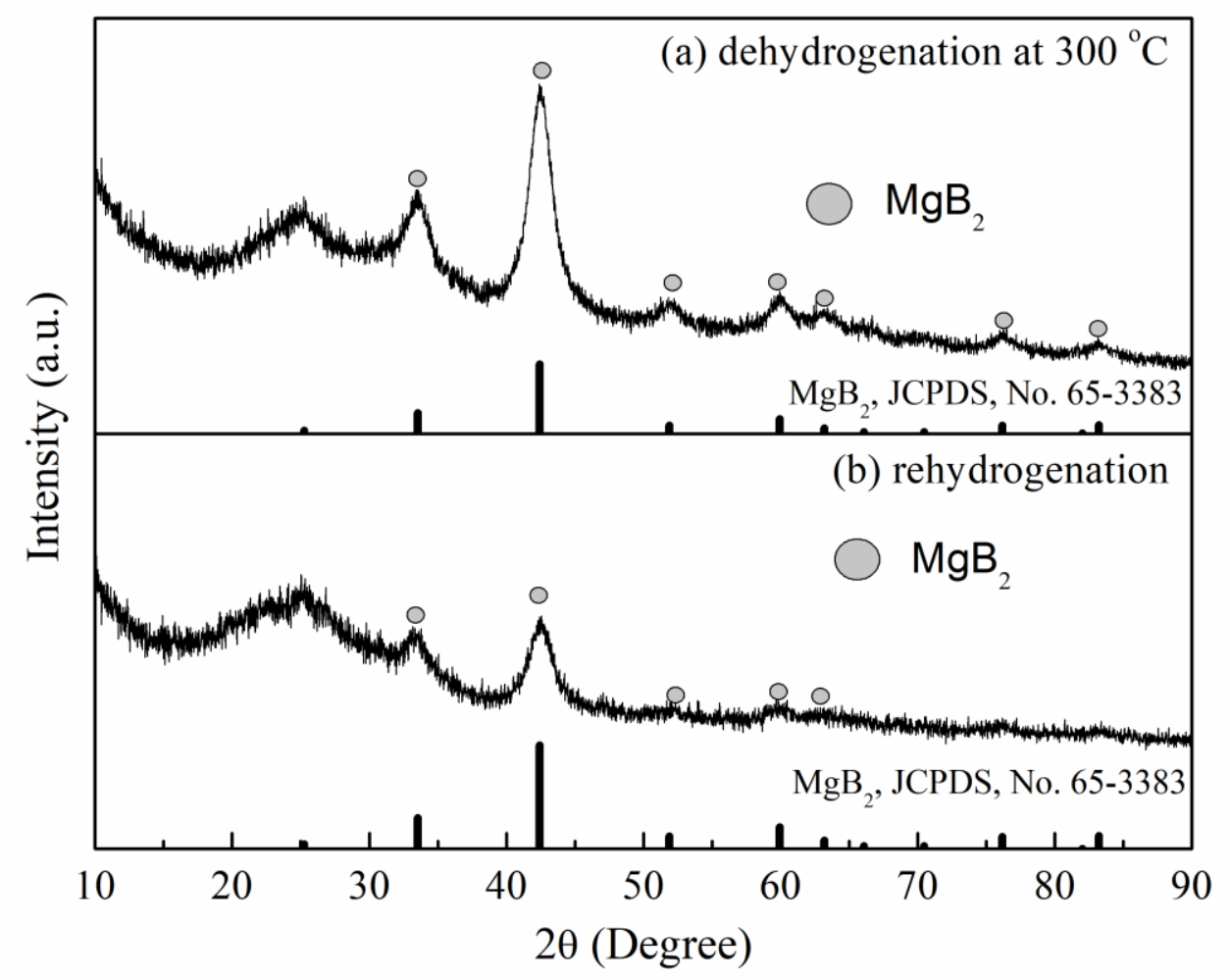

Figure S10. XRD patterns of the as-synthesized MBH-Gr after dehydrogenation to $300{ }^{\circ} \mathrm{C}$ (a), and its products rehydrogenated at $300{ }^{\circ} \mathrm{C}$ (b) under a hydrogen pressure of $100 \mathrm{~atm}$. 


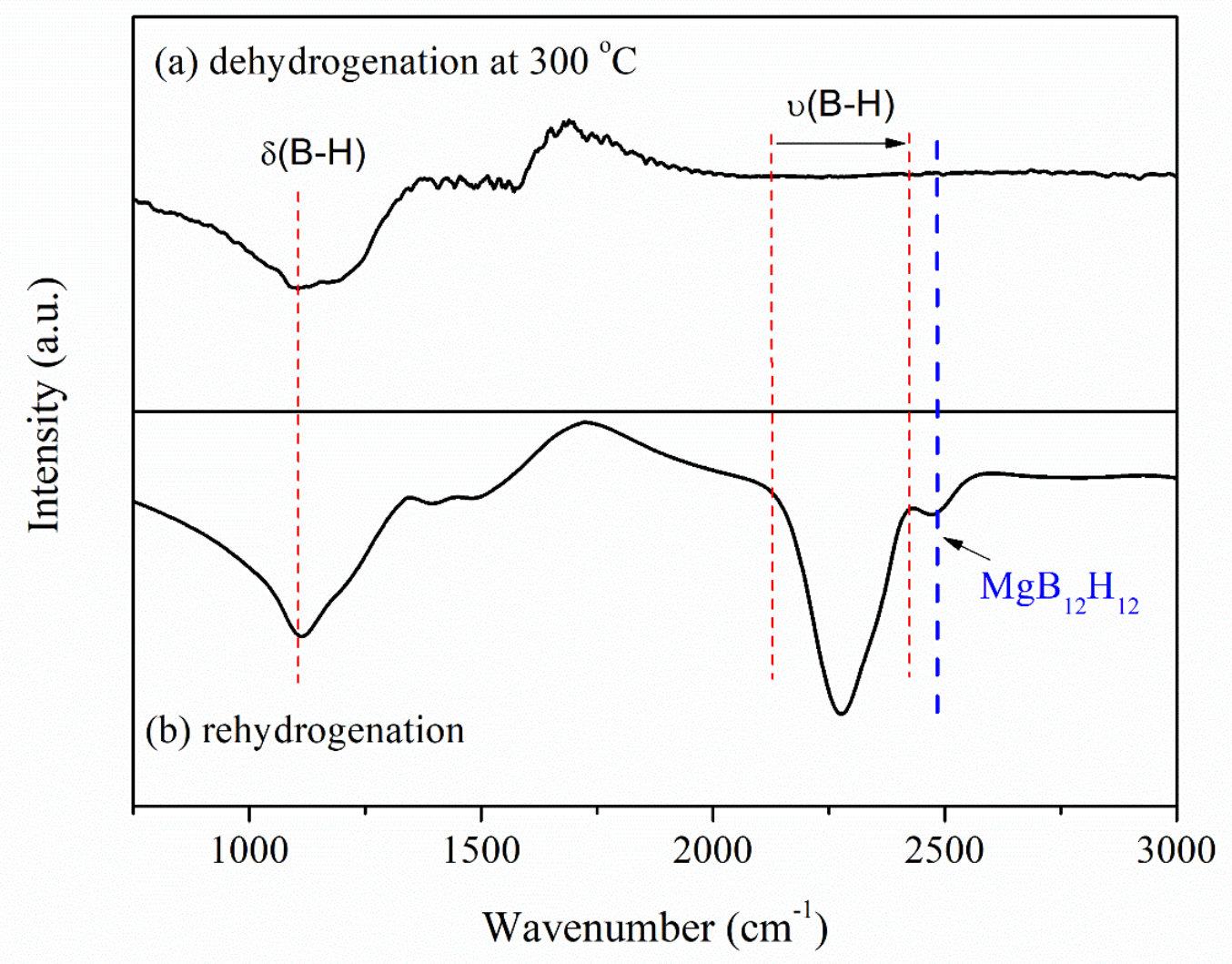

Figure S11. FTIR spectra of the as-synthesized MBH-Gr dehydrogenated to $300{ }^{\circ} \mathrm{C}$ (a) and its products rehydrogenated at $300{ }^{\circ} \mathrm{C}(\mathrm{b})$ under a hydrogen pressure of $100 \mathrm{~atm}$. 
WILEY-VCH

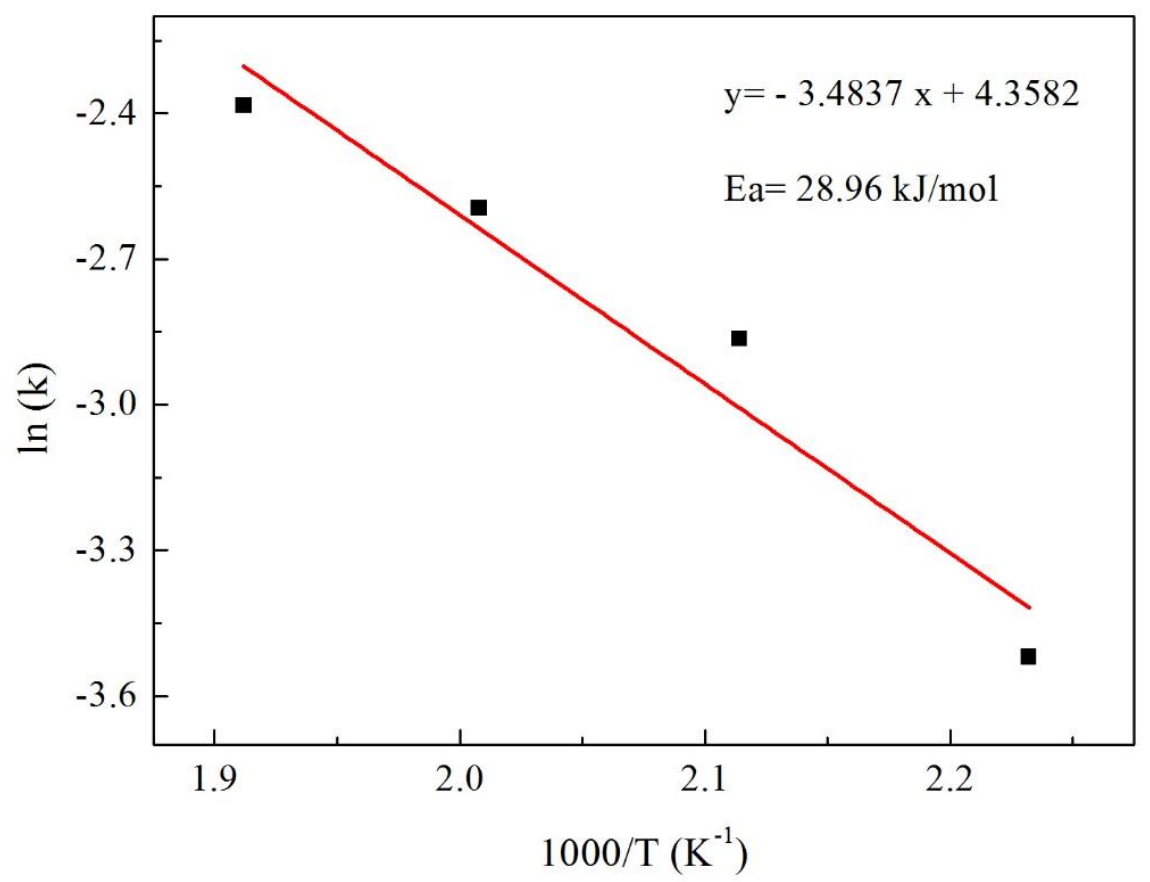

Figure S12. Arrhenius profile according to the dehydrogenation kinetics of the as-synthesized MBH-Gr.

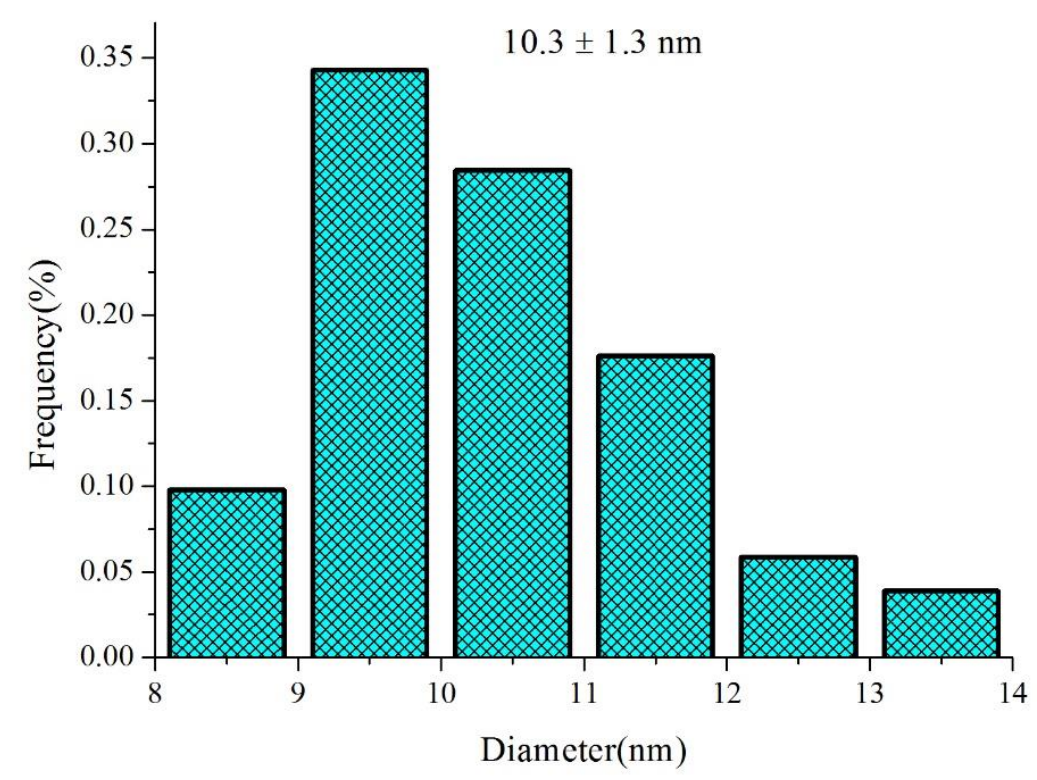

Figure S13. Particle size distribution of the as-synthesized MBH-Gr after 3 cycles of dehydrogenation. 


\section{WILEY-VCH}

Table S1. Comparison of loading amount of some reported $\mathrm{Mg}\left(\mathrm{BH}_{4}\right)_{2}$ samples confined in support materials.

\begin{tabular}{|c|c|l|c|}
\hline & Loading of $\mathrm{Mg}\left(\mathrm{BH}_{4}\right)_{2}$ & Supporting materials & Reference \\
\hline 1 & $44 \mathrm{wt} \%$ & Activated carbon & S7 \\
\hline 2 & $25 \mathrm{wt} \%$ & Pyrazine & S8 \\
\hline 3 & $40 \mathrm{wt} \%$ & CMK-3 & S9 \\
\hline 4 & $45 \mathrm{wt} \%$ & CMK-3 & S10 \\
\hline 5 & $6 \mathrm{wt} \%$ & Carbon aerogel/KS-6 & S11 \\
\hline 6 & Less than $18 \mathrm{wt} \%$ & Porous carbon & S13 \\
\hline 7 & $50 \mathrm{wt} \%$ & CNTs & This work \\
\hline 8 & $60 \mathrm{wt} \%$ & graphene & \\
\hline
\end{tabular}




\section{WILEY-VCH}

Table S2. Comparison of reversible hydrogen storage capacity of graphene-supported $\operatorname{Mg}\left(\mathrm{BH}_{4}\right)_{2}$ NPs with others in the literature.

\begin{tabular}{|c|c|c|c|c|}
\hline Sample & $\begin{array}{c}\mathrm{H}_{2} \text { absorption } \\
\text { (Temperature, } \\
\text { hydrogen pressure) }\end{array}$ & $\begin{array}{l}\mathrm{H}_{2} \text { desorption } \\
\text { (Temperature) }\end{array}$ & Capacity & Reference \\
\hline $\begin{array}{l}\mathrm{Mg}\left(\mathrm{BH}_{4}\right)_{2}- \\
\text { Silica aerogel } \\
\text { microparticles }\end{array}$ & $390^{\circ} \mathrm{C}, 110 \mathrm{~atm}$ & $400{ }^{\circ} \mathrm{C}$ & $\begin{array}{l}2.9 \text { wt. } \% \\
\left(3^{\text {rd }} \text { cycle }\right)\end{array}$ & S14 \\
\hline $\begin{array}{c}\mathrm{Mg}\left(\mathrm{BH}_{4}\right)_{2}-2 \\
\mathrm{~mol}_{\%} \mathrm{CoCl}_{2}\end{array}$ & $\sim 282{ }^{\circ} \mathrm{C}, \sim 120 \mathrm{~atm}$ & $286^{\circ} \mathrm{C}$ & $\begin{array}{l}2.0 \text { wt. } \% \\
\left(3^{\text {rd }} \text { cycle }\right)\end{array}$ & S15 \\
\hline $\begin{array}{c}\mathrm{Mg}\left(\mathrm{BH}_{4}\right)_{2}-2 \\
\mathrm{~mol} \mathrm{TiO}_{2}\end{array}$ & $271^{\circ} \mathrm{C}, 140 \mathrm{~atm}$ & $271^{\circ} \mathrm{C}$ & $\begin{array}{l}2.4 \text { wt. } \% \\
\left(2^{\text {nd }} \text { cycle }\right)\end{array}$ & S16 \\
\hline $\begin{array}{c}\mathrm{Mg}\left(\mathrm{BH}_{4}\right)_{2}- \\
50 \mathrm{wt} \% \text { Carbon } \\
\text { nanotubes }\end{array}$ & $300^{\circ} \mathrm{C}, 100 \mathrm{~atm}$ & $300{ }^{\circ} \mathrm{C}$ & $\begin{array}{l}1.4 \text { wt. } \% \\
\left(2^{\text {nd }} \text { cycle }\right)\end{array}$ & S13 \\
\hline $\begin{array}{c}\mathrm{Mg}\left(\mathrm{BH}_{4}\right)_{2}-2 \\
\mathrm{~mol}_{\%} \mathrm{Co}_{3} \mathrm{O}_{4}\end{array}$ & $\sim 285^{\circ} \mathrm{C}, \sim 116 \mathrm{~atm}$ & $285^{\circ} \mathrm{C}$ & $\begin{array}{l}1.4 \text { wt. } \% \\
\left(3^{\text {rd }} \text { cycle }\right)\end{array}$ & S15 \\
\hline $\begin{array}{c}\mathrm{Mg}\left(\mathrm{BH}_{4}\right)_{2}-2 \\
\mathrm{~mol} \% \mathrm{Co}_{3} \mathrm{O}_{4}\end{array}$ & $\sim 285^{\circ} \mathrm{C}, \sim 116 \mathrm{~atm}$ & $285^{\circ} \mathrm{C}$ & $\begin{array}{l}1.4 \text { wt. } \% \\
\left(3^{\text {rd }} \text { cycle }\right)\end{array}$ & S15 \\
\hline $\begin{array}{c}\mathrm{Mg}\left(\mathrm{BH}_{4}\right)_{2}-2 \\
\mathrm{~mol} \% \mathrm{Co}_{2} \mathrm{~B}\end{array}$ & $\sim 283^{\circ} \mathrm{C}, \sim 122 \mathrm{~atm}$ & $286{ }^{\circ} \mathrm{C}$ & $\begin{array}{l}1.5 \text { wt. } \% \\
\left(3^{\text {rd }} \text { cycle }\right)\end{array}$ & S15 \\
\hline $\begin{array}{c}\text { Graphene- } \\
\text { supported } \\
\mathrm{Mg}\left(\mathrm{BH}_{4}\right)_{2} \mathrm{NPs}\end{array}$ & $300^{\circ} \mathrm{C}, 100 \mathrm{~atm}$ & $250{ }^{\circ} \mathrm{C}$ & $\begin{array}{l}4.13 \text { wt. } \% \\
\left(2^{\text {nd }} \text { cycle }\right) \\
3.24 \text { wt. } \% \\
\left(6^{\text {th }} \text { cycle }\right)\end{array}$ & $\begin{array}{l}\text { This } \\
\text { work }\end{array}$ \\
\hline
\end{tabular}




\section{WILEY-VCH}

\section{References:}

[S1] G. L. Xia, Y. B. Tan, X. W. Chen, D. L. Sun, Z. P. Guo, H. K. Liu, L. Z. Ouyang, M.

Zhu, X. B. Yu, Adv. Mater. 2015, 27, 5981.

[S2] C. Lu, J. X. Zou, X. Y. Shi, X. Q. Zeng, W. J. Ding, Int. J. Hydrogen Energy 2017, 42, 2239.

[S3] P. C. Hohenberg, W. Kohn, Phys. Rev. 1964, 136, B864.

[S4] J.P. Perdew, Y. Wang, Phys. Rev. B 1992, 45, 13244.

[S5] B. Delley, J. Chem. Phys. 1991, 94, 7245.

[S6] J. D. Pack, H. J. Monkhorst, Phys. Rev. B 1977, 16, 1748.

[S7] M. Fichtner, Z. Zhao-Karger, J. J. Hu, A. Roth, P. Weidler, Nanotechnology 2009, 20, 204029.

[S8] M. J. Ingleson, J. P. Barrio, J. Bacsa, A. Steiner, G. R. Darling, J. T. A. Jones, Y. Z. Khimyak, M. J. Rosseinsky, Angew. Chem. Int. Ed. 2009, 48, 2012.

[S9] A. Ampoumogli, Th. Steriotis, P. Trikalitis, D. Giasafaki, E. G. Bardaji, M. Fichtner, G. Charalambopoulou, J. Alloys Compd. 2011, 509S, S705.

[S10] M. A. Wahab, Y. Jia, D. Yang, H. Zhao, X. Yao, J. Mater. Chem. A 2013, 1, 3471.

[S11] Y. G. Yan, Y. S. Au, D. Rentsch, A. Remhof, P. E. de Jongh, A. Züttel, J. Mater. Chem. A $2013,1,11177$.

[S12] Y. S. Au, Y. G. Yan, K. P. de Jong, A. Remhof, and P. E. de Jongh, J. Phys. Chem. C 2014, 118, 20832.

[S13] M. Han, Q. Zhao, Z. Z. Zhu, Y. X. Hu, Z. L. Tao and J. Chen, Nanoscale 2015, 7, 18305.

[S14] M. Rueda, L. M. Sanz-Moral, A. Girella, P. Cofrancesco, C. Milanese, A. Martin, Int. J. Hydrogen Energy, 2016, 41, 15245. 


\section{WILEY-VCH}

[S15] O. Zavorotynska, I. Saldan, S. Hion, T. D. Humphries, S. Deledda, B. C. Hauback, J.

Mater. Chem. A 2015, 3, 6592.

[S16] I. Saldan, C. Frommen, I. Llamas-Jansa, G. N. Kalantzopoulos, S. Hino, B. Arstad, R.

H. Heyn, O. Zavorotynska, S. Deledda, M. H. Sorby, H. Fjellvag, B. C. Hauback, Int. J. Hydrogen Energy 2015, 40, 12286. 